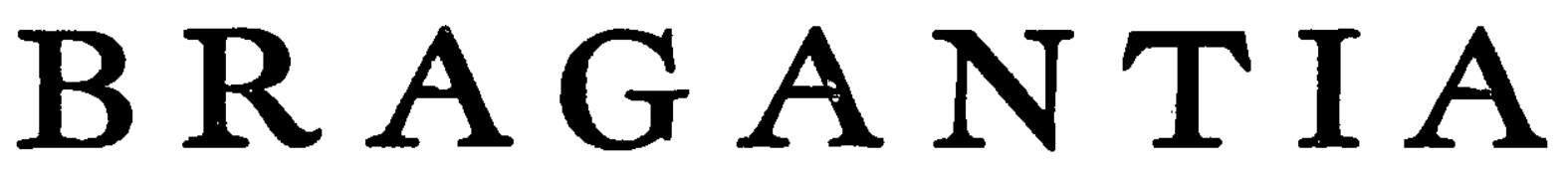

Boletim Técnico da Divisão de Experimentação e Pesquisas IN STITUTO AGRONÖMICO

Vol. 6 Campinas, Setembro de $1946 \quad$ N. 9

\title{
O SISTEMA RADICULAR DO CAFEEIRO NOS PRINCIPAIS TIPOS DE SOLO DO ESTADO DE SÃO PAULO
}

Coaraci M. Franco

Q

Romeu Inforzato

\section{INTRODUÇÃO}

Ao traçarmos um plano de estudos sôbre a fisiologia do cafeeiro em relação à água, visando principalmente a questão do sombreamento dos cafezais, puzemos em primeira linha o estudo do seu sistema radicular. A extensão, profundidade, percentagem de raízes nas diversas camadas de solo, etc., são fatôres que preciøamos conhecer bem para uma boa compreensão sôbre a concorrência que as árvores de sombra possam fazer aos cafeeiros por elas sombreados.

Além disso, muitas outras vantagens poderão advir dêstes estudos, tuis como: novas orientações sôbre a adubação e tratos culturais do cafezal, ou um espaçamento melhor, de maneira a aproveitar no máximo o terreno sem, contudo, provocar séria concorrência entre as raízes dos cafeeiros. No caso de irrigação, a profundidade que deverá ser levada em conta nos cáleulos da quantidade de água, etc., são pontos que se tornarão mais claros com um melhor conhecimento do sistema radicular do cafeeiro.

A conformação do sistema radicular de uma planta depende, em primeiro lugar, da sua constituição genética. Plantas genèticamente Tênticas, vegetando no mesmo solo, têm sistemas radiculares com a mesma conformação. As condições de solo podem, porém, induzir reações no sistema radicular que modificarão a sua conformação e desenvolvimento e, por isto, é diferente o sistema radicular de plantas genotipicamente idênticas, mas crescendo em solos diferentes. 
Entre os fatôres que mais influem na conformação do sistema radicular, queremos pôr em evidência a fertilidade do solo, o seu teor em umidade e a sua aeração.

Se as diversas camadas do solo não são homogêneas quanto às suas propriedades físicas e químicas, serả diferente a conformação do sistema radicular dentro de cada uma dessas camadas.

E sabido que as raízes se desenvolvem mais nas camadas mais férteis do solo, onde encontram mais elementos nutritivos para o seu crescimento.

A água é indispensável para o crescimento das raízes, desde que sem ela não é possível existir vida e muito menos crescimento. Água demais, porém, prejudica as raízes por tomar o lugar do ar no solo, o que resulta em deficiência de oxigênio para a respiração das raízes. Nestas condições, as raízes crescem e subdividem-se menos. Em um solo com pequena umidade e boa aeração, as raízes erescem e se subdividem mais profusamente, o que resulta em uma superfície de absorção muito maior.

Também a aeração influi sôbre a absorção dos elementos minerais pelas raízes, pois o oxigênio é necessário para a respiração das raízes e é êste processo que fornece energia para a absorção.

Estas breves considerações são suficientes para dar uma idéia de como são complexos os fatôres que podem influenciar sôbre o desenvolvimento e conformação do sistema radicular de uma planta.

E sendo assim, o estudo do sistema radicular deve ser feito em diferentes tipos de solo, já que os resultados encontrados em um não podem ser aproveitados para outros.

Diante disto fizemos o estudo do sistema radicular do cafeeiro nos principais tipos de solo do Estado de São Paulo, que são: terra-roxa misturada, em Campinas e Jaú; terra-roxa legítima, em Ribeirão Preto; terra massapé-salmourão, em Ibiti, município de Amparo e terra baurusuperior, em Pindorama.

\section{BREVE REVISÃO DA LITERATURA}

Dafert e Toledo Braga (2) parece-nos que foram os primeiros que publicaram dados referentes ao sistema radicular do cafeeiro.

Em seu estudo sôbre o pêso das diferentes partes do cafeeiro para fins de cálculo de adubação, aquêles autores obtiveram o comprimento e pêso do sistema radicular daquela planta em diversas idades. Para cafeeiros de 10 e 40 anos, acharam 0,64 e $0,95 \mathrm{~m}$, respectivamente, para o comprimento da raiz e 20.160 e 47.850 gr para os respectivos pesos do sistema radicular.

Em se tratando de um estudo dos pesos das diferentes partes da árvore e não de um estudo do sistema radicular, aquêles autores desprezaram, por certo, as radicelas que foram além daquelas profundidades, jâ que o seu pêso é insignificante em relação ao pêso das raízes principais, 
como veremos mais adiante. $\mathrm{E}$ cremos ter sido esta a razão por que deram, como comprimento das raízes, aquelas pequenas dimensões.

Nutman (6) e (7) estudou o sistema radicular do cafeeiro em diversos tipos de solo da África Inglêsa. A téenica por êle empregada foi a de abrir uma valeta rente à planta e expor as raízes por meio de um jacto de água. As raízes eram presas em suas posições naturais por meio de pinos. Tna tela metálica de malhas grandes era colocada em frente e as raízes desenhadas em escala sôbre um papel quadriculado.

Êste autor chegou à conclusão de que o sistema radicular de um cafeeiro de 5 a 6 anos já tem a sna conformação definida. A profundidade máxima encontrada foi de $4,06 \mathrm{~m}$ em um solo profundo e a mínima foi de $0,23 \mathrm{~m}$ em um solo onde o lençol dágua estava apenas a $0,46 \mathrm{~m}$ da superfície. Conclui também Nutman que o $\mathrm{pH}$ ótimo para o desenvolvimento das raízes do cafeeiro esté entre 5,8 e 6,0 e que o "die-back" causado nos ramos pela super-produção da árvore acarreta também a morte de muitas raízes.

Em outro trabalho, Nutman (8) cavou uma valeta rente à planta, colocou na parede junto a ela uma tela cujas malhas tinham um pé quadrado de área e desmanchou com jacto de água cada pé cúbico de solo, por sua vez. As raízes de cada pé cúbico eram retiradas e pesadas e medido o comprimento total de raízes. Do número, diâmetro e comprimento de radicelas contidas nessa parede de um pé de espessura, aquêle autor caleulou o número, comprimento total das radicelas da planta tôda e a superfícic total de absorção do sistema radicular inteiro.

Em um único bloco de 1 pé cúbieo, Nutman encontrou 150.000 radicclas, num total de 580 metros. Em quatro árvores estudadas, encontrou os seguintes comprimentos totais de radicelas em $\mathrm{Km}: 15,3762 ; 20,3281$; 82,6707 c 23,9884, o que dá uma média de $22,7651 \mathrm{Km}$ de radicelas por árvore.

As áreas totais de superfície absorvente foram, respectivamente, em $\mathrm{m}^{2}: 313 ; 414 ; 665 ; 489$, dando uma média de $463 \mathrm{~m}^{2}$ de raízes por planta.

Trench (9) empregou a téenica de desenterrar as raízes com jacto de ńgua. Diz êste autor que o sistema radicular não é uma cousa estática e que os métodos de adubacão e tratos culturais podem introduzir modificações. Assim é que, eom subsolagem, obteve um aprofundamento maior das raízes superficiais. A profundidade mâxima das raízes encontrada foi de 2,70 .

Beckley (1) encontrou, como Nutman (7), um "die-back" também nas raízes, correspondendo ao "die-back" dos ramos, o que reduz e deforma o sistema radicular primitivo.

Guiseafré-Arrilaga e Gomez (3) estudaram o sistema radicular do cafeeiro da seguinte maneira: tomaram 6 plantas em linha e escavaram o solo em blocos de $11 \mathrm{~m}$ pé cúbico de cada vez, compreendendo tôdas as árvores até a profundidade de quatro pés, retirando, assim, aos poucos, todo o sistema radicular das plantas. 
Êsses blocos eram peneirados e as raízes separadas e pesadas depois de sêcas ao ar.

Noventa e quatro por cento do pêso total de raízes foram encontrados na primeira camada de $30,5 \mathrm{~cm}$ de profundidade, sendo isto atribuído à maior riqueza do solo em matéria orçânica na superfície e à melhor aeração. Dizem, os autores em questão, que o diâmetro do tronco dá melhores indicações sôbre o desenvolvimento do sistema radicular do cafeeiro do que a altura ou tamanho da árvore.

A penetração vertical das raízes de um cafeeiro de 7 anos foi de $0,91 \mathrm{~m}$ e a extensão lateral de $1,22 \mathrm{~m}$ no solo cstudado.

Dos estudos feitos concluiram ainda aquêles autores que os cafeeiros devem ser plantados a uma distância mínima de $2,44 \times 2,44$ metros a fim de evitar séria concorrêneia entre as raízes das plantas vizinhas e que o sistema radicular pode ser induzido a uma penetração mais profunda no solo, fazendo-se valetas entre as linhas.

Em um segundo trabalho, Guiscafré-Arrilaga e Gomez (4) estudaram, pelo mesmo método empregado no sen primeiro trabalho, o sistema radicular do cafeeiro em outro tipo de solo.

Encontraram 95\% do pêso total das raízes na primeira camada de $0,30 \mathrm{~m}$ de solo.

Enquanto no primeiro solo estudado, a relação do pêso das partes néreas para o pêso das raízes variou bastante, neste segundo tipo de solo (Catalina) essa relação foi constante e de $3: 1$.

Guiseafré- $\Lambda$ rrilaga e Gomez (5) estudaram ainda, pelo mesmo método, o sistema radicular de 6 cafeeiros com 21 anos de idade, no mesmo solo a que se refere o trabalho anterior.

Concluiram então que o sistema radicular do cafeeiro nessa idade segue a mesma distribuição no solo que o de uma planta nova. Assim é que $94 \%$ do pêso das raízes foram encontrados na primeira camada de $0,30 \mathrm{~m}$ e a razão do pêso das partes aéreas para o pêso das raízes foi de $4: 1$.

\section{MÉTODO}

O método por nós usado é uma modificação do método de GuiscafréArrilaga e Gomez (3), ao qual jâ nos referimos na introdução; consiste essa modificação em se retirar do solo as raízes compreendidas em uma parede de $0,30 \mathrm{~m}$ de espessura, conforme se verá mais adiante, ao invés de retirar o sistema radicular inteiro.

Êste método reduz muito o trabalho e, além de mais econômico, facilita o estudo de maior número de plantas.

Quatro árvores em linha foram escolhidas no meio do cafezal. À distância de $0,15 \mathrm{~m}$ do centro do troneo das árvores, que foram cortadas rente ao solo, abriu-se uma valeta que se aprofundou até onde não mais se encontravam raízes dos cafeeiros. 
A largura foi de cêrca de um metro, suficiente para que os dois operârios que trabalhavam pudessem manejar livremente as ferramentas. A fig. I mostra a valeta pronta. A parede junto aos troncos das árvores foi cuidadosamente feita, de maneira a ficar bem vertical, lisa e exatamente a $0,15 \mathrm{~m}$ do centro dos troncos.

Isto feito, foi essa mesma parede desmanchada em blocos de $30 \mathrm{~cm}$ de comprimento por $30 \mathrm{~cm}$ de largura. Nas primeiras três camadas, os blocos foram retirados com $10 \mathrm{~cm}$ de altura, nas duas seguintes $\left(4^{\mathrm{a}}\right.$ e $\left.5^{\mathrm{a}}\right)$ com $20 \mathrm{~cm}$ e nas demais com $30 \mathrm{~cm}$, portanto, cubos de $0,30 \mathrm{~cm}$ de aresta. Antes de se retirar a primeira camada pròpriamente dita, de $10 \mathrm{~cm}$ e a fim de nivelar o terreno, tirava-se uma camada superficial, de altura irregular em consequência do desnível do solo.

Em Campinas, a parede de terra retirada produziu 456 blocos. Tirávamos assim um. "perfil" do sistema radicular das plantas. A fig. II foi tomada quando era retirada em Campinas a terceira camada de blocos, vendo-se, em cima, sacos contendo os blocos já retirados. Para maior facilidade, as raízes maiores foram deixadas por algum tempo no local, sendo apenas assinalados os lugares onde deveriam ser cortadas. Mais tarde foram serradás nos pontos assinalados e os pedaços colocados junto com a terra do seu respectivo bloco.

Cada bloco foi cuidadosamente desmanchado e peneirado de maneira a bem separar as raízes da terra, sem perda de radicelas.

$\Lambda$ s raízes foram lavadas ràpidamente, secadas à sombra e pesadas.

Tínhamos assim o pêso das raízes existentes em cada um dos blocos. Mas o estudo da distribuição das raízes por pêso, não dá uma idéia real sob o ponto de vista fisiológico da absorção. Centenas de gramas de raízes nas froximidades do tronco podem representar apenas uma única raiz muito volumosa, ao passo que algumas gramas, nas partes mais distantes, poderão representar muitos metros de pequeninas radicelas, exatamente as mais importantes sob o ponto de vista da absorção de água e sais ninerais pela planta.

A julgar pela distribuição das raízes por pêso, o sistema radicular dos cafeeiros de Campinas, por exemplo, seria péssimo, pois que $91 \%$ do pêso total das raízes estão nos primeiros $30 \mathrm{~cm}$ de solo. Ao contrário, porém, como veremos no próximo capítulo, o sistema radicular dos cafeeiros no solo de Campinas é ótimo, de vez que enorme quantidade de radicelas se aprofundam no solo.

Para atenuar êste inconveniente construimos gráficos por pontos, dando a cada ponto o valor de 0,1 gr. Por êsses gráficos já se percebe que a grande percentagem do pêso das raízes encontradas nas camadas superficiais é devida ao grande pêso das raízes primárias, superficiais.

$O$ inconveniente do julgamento do sistema radicular pela sua distribuição por pêso foi, porém, inteiramente eliminado com o emprêgo de fotografias, tendo sido usado o seguinte processo: um pano preto foi quadriculado e cada quadro representava o perfil de um bloco retirado 
do terreno em seu tamanho natural. As irregularidades da superfície do terreno foram também anotadas e reproduzidas sôbre o pano preto. As raízes retiradas de cada bloco foram distribuídas sôbre o pano, dentro do quadro a êle correspondente. Assim, a fotografia dava uma visão real do perfil do sistema radicular dos cafeeiros, tal como se achava no solo. Pela fotografia podíamos então avaliar a eficiência do sistema radicular das plantas em estudo, nas suas diferentes partes, pela quantidade de radicelas presentes nas partes consideradas.

\section{CÁLCULO DO PÊSO TOTAL DO SISTEMA RADICULAR}

O solo ocupado pelo sistema radicular de um cafeeiro é o compreendido no prisma reto de terra que tem por base o quadrado do espaçamento entre as árvores, no caso mais geral de uma plantação em quadrado, ocupando a planta em consideração o centro dêsse quadro. As raízes da planta que ultrapassam êsse prisma são compensadas pelas raízes das plantas vizinhas que entram nesse mesmo prisma.

$\mathrm{Na}$ fig. III, $a b c d$ representa a área ocupada por um cafeeiro que se encontra no centro do quadro So., sendo efgh a parede de $30 \mathrm{~cm}$ de espessura que foi desmanchada em blocos para retirarmos as raízes. São conhecidos os pesos de raízes que existiam em cada um dos prismas de solo que têm por base os quadrados $S_{0} ; S_{1} ; S_{2}$, etc. Admitindo certa simetria no sistema radicular, podemos calcular aproximadamente o pêso de raízes existentes sob cada coroa de solo representadas na fig. III, por uma simples proporção entre as áreas conhecidas dos dois quadrados existentes em cada coroa, o pêso de raízes sob êles encontrado e a área total da coroa. Os erros resultantes de não serem os quadrados perfeitamente incluídos pelos dois círeulos sucessivos, além de pequenos se compensam. A área $\Lambda_{\text {I }}$ não é pròpriamente uma coroa desde que é composta da área do primeiro círculo menos o quadrado So.

As áreas de So, $A_{I}$ e das coroas $A_{I I} A_{\text {III }} A_{I V} A_{V}$ e $A_{V I}$ são:

$$
\begin{aligned}
& \mathrm{S}_{\mathrm{o}}=(2 \mathrm{r})^{2}=4 \mathrm{r}^{2} \\
& \mathrm{~A}_{\mathrm{I}}=\pi(3 \mathrm{r})^{2}-4 \mathrm{r}^{2}=\mathrm{r}^{2}(9 \pi-4) \\
& \mathrm{A}_{\mathrm{II}}=\pi(5 \mathrm{r})^{2}-\pi(3 \mathrm{r})^{2}=16 \pi \mathrm{r}^{2} \\
& \mathrm{~A}_{\mathrm{III}}=\pi(7 \mathrm{r})^{2}-\pi(5 \mathrm{r})^{2}=24 \pi \mathrm{r}^{2} \\
& \mathrm{~A}_{\mathrm{IV}}=\pi(9 \mathrm{r})^{2}-\pi(7 \mathrm{r})^{2}=32 \pi \mathrm{r}^{2} \\
& \mathrm{~A}_{\mathrm{V}}=\pi(11 \mathrm{r})^{2}-\pi(9 \mathrm{r})^{2}=40 \pi \mathrm{r}^{2} \\
& \mathrm{~A}_{\mathrm{VI}}=\pi(13 \mathrm{r})^{2}-\pi(11 \mathrm{r})^{2}=48 \pi \mathrm{r}^{2}
\end{aligned}
$$

Como dissemos anteriormente, o pêso das raízes existente sob cada uma dessas áreas pode ser calculado por uma proporção entre o pêso de raízes encontrado sob os dois quadrados existentes em cada uma das áreas 
$A_{I} \Lambda_{I I} \Lambda_{I I I}$, ete., a superfície dêsses dois quadrados e a superfície total daquelas áreas.

Então, sendo $\mathrm{PS}_{0}$ o pêso de raízes encontrado sob o quadrado $\mathrm{S}_{0}$; $\mathrm{PS}_{1}$ o pêso de raízes encontrado sob o quadrado $\mathrm{S}_{1}$, $\mathrm{PS}_{2}$ o pêso de raízes encontrado sob o quadrado $S_{62} ; P_{1}$ o pêso de raízes existente sob a área

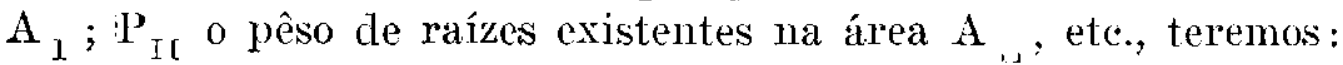

$$
\begin{aligned}
& \frac{8 \mathrm{r}^{2}}{\mathrm{r}^{2}(9 \pi-4)}:=\frac{P \mathrm{~S}_{1}+\mathrm{PS}_{2}}{\mathrm{P}_{\mathrm{I}}} \therefore \mathrm{P}_{\mathrm{I}}=\frac{\left(9_{\pi}-4\right)\left(\mathrm{PS}_{1}+\mathrm{PS_{2 }}\right)}{8} \\
& \frac{8 \mathrm{r}^{2}}{16 \pi \mathrm{r}^{2}}=\frac{\mathrm{PS}_{3}+\mathrm{PS}_{4}}{\mathrm{P}_{\mathrm{II}}} \therefore \mathrm{P}_{\mathrm{II}}=2 \pi\left(\mathrm{PS}_{3}+\mathrm{PS}_{4}\right) \\
& \frac{8 \mathrm{r}^{2}}{24 \pi \mathrm{r}^{2}}=\frac{P S_{5}+\mathrm{P}_{6}}{\mathrm{P}_{\mathrm{III}}} \therefore \mathrm{P}_{\mathrm{III}}=3 \pi\left(\mathrm{PS}_{5}+\mathrm{PS}_{6}\right) \text { e por }
\end{aligned}
$$

deduçoes semelhantes encontraremos:

$$
\begin{aligned}
& \mathrm{P}_{\mathrm{IV}}=4 \pi\left(\mathrm{PS}_{7}+\mathrm{PS}_{8}\right) \\
& \mathrm{P}_{\mathrm{V}}=\overline{2}\left(\mathrm{PS}_{9}+\mathrm{PS}_{10}\right) \\
& \mathrm{P}_{\mathrm{VI}}=6 \pi\left(\mathrm{PS}_{11}+\mathrm{PS}_{12}\right)
\end{aligned}
$$

O pêso total $P_{t}$, do sistema radicular será:

$$
\begin{aligned}
& \mathrm{P}_{\mathrm{t}}=\mathrm{PS}_{0}+\frac{(9 \pi-4)\left(\mathrm{PS}_{1}+\mathrm{PS}_{2}\right)}{8}+2 \pi\left(\mathrm{PS}_{3}+\mathrm{PS}_{4}\right)+3 \pi\left(\mathrm{PS}_{5}\right. \\
& \left.+\mathrm{PS}_{6}\right)+4 \pi\left(\mathrm{PS}_{7}+\mathrm{PS}_{8}\right)+5 \pi\left(\mathrm{PS}_{9}+\mathrm{PS}_{10}\right)+6 \pi\left(\mathrm{PS}_{11}+\mathrm{PS}_{12}\right) .
\end{aligned}
$$

Fazendo-se as simplificações teremos:

$$
\begin{aligned}
\mathrm{P}_{\mathrm{\imath}}= & \mathrm{PS}_{0}+3,03\left(\mathrm{PS}_{1}+\mathrm{PS}_{2}\right)+\pi\left[2\left(\mathrm{PS}_{3}+\mathrm{PS}_{4}\right)+3\left(\mathrm{PS}_{5}+\mathrm{PS}_{6}\right)\right. \\
& \left.+4\left(\mathrm{PS}_{7}+\mathrm{PS}_{8}\right)+5\left(\mathrm{PS}_{0}+\mathrm{PS}_{10}\right)+6\left(\mathrm{PS}_{11}+\mathrm{PS}_{12}\right)\right]
\end{aligned}
$$

Com esta fórmula calculamos os pesos dos sistemas radiculares dos cafeeiros conhecendo-se os pesos de raízes tirados dos prismas de terra $\mathrm{S}_{0}, \mathrm{~S}_{1}, \mathrm{~S}_{2}, \mathrm{~S}_{3}, \mathrm{~S}_{4}$, etc.

Vemos, contudo, que sobraram nos cantos do quadrado abcd quatro triângulos que não entraram nos cálculos. A área da coroa maior $\Lambda_{\mathrm{VI}}$ é $37,7 \mathrm{~cm}^{2}$ e sob ela achamos no caso máximo $1327 \mathrm{gr}$ de raízes.

As áreas daqueles triângulos que sobram, somadas, dão $22,2 \mathrm{~cm}^{2}$. Admitindo-se nêles a mesma densidade de raízes que na coroa $\Lambda_{\mathrm{VI}}$ teriam êles $783 \mathrm{gr}$ de raízes, o que é apenas $3,1 \%$ do total de raízes da planta, que foi de $25.068 \mathrm{gr}$. Mas a densidade de raízes nos referidos triângulos é menor do que na coroa $\Lambda_{\text {vI }}$ por se acharem mais distantes do tronco da planta e o êrro, portanto, deverá ser ainda menor do que $3,1 \%$. 
Vemos também na fig. III que, em virtude de haver uma pequena variação no espaçamento entre as plantas, a última coroa ultrapassou um pouco em dois lados os limites da área ocupada pelas raízes do cafeeiro, indo um pouco além das linhas ab e bc. E como êste foi o caso mais frequentemente encontrado, dêle nos valemos para ilustração dêste trabalho. A área total dos dois seguimentos que ultrapassam o quadrado $a b c d$ é $8,8 \mathrm{~cm}^{2}$. Por um raciocínio idêntico ao anterior, concluimos que o pêso de raízes existente sob essas áreas é de $310 \mathrm{gr}$ e isto representa apenas $1,2 \%$ do pêso total do sistema radicular. Além disto, serve para compensar em parte o pequeno êrro proveniente de não terem entrado nos cálculos as raízes existentes sob os triângulos que ocupam os cantos do quadrado $a b c d$ se bem que os presentes cálculos dão valores apenas aproximados, desde que é necessária a hipótese de ter o sistema radicular certa simetria que, provàvelmente, nem sempre existe.

\section{RESULTADOS}

\section{1) Sistema radicular do cafeeino na terra roxa misturada de Campinas}

Vemos no gráfico I a representação, por pontos, do sistema radicular dos cafeeiros na terra roxa misturada da Estação Experimental Santa Elisa, em Campinas. Consoante já indicado no gráfico, cada ponto representa $0,1 \mathrm{gr}$ de raiz ou cada 10 pontos representam uma gr.

Convém salientar que, quando se trata de radicelas finíssimas, 1 grama é quantidade considerável de raiz e representa uma superfície de absorção também considerấvel.

Como vemos, as raízes neste tipo de solo vão além de 2,50 metros, o que se deduz do fato de ainda existirem algumas radicelas nos últimos blocos retirados àquela profundidade. A escavação deveria, portanto, continuar, mas, à primeira vista, parecia já não existir radicela nos últimos blocos retirados e por isso foi o serviẹo dado por terminado e a valeta cheia novamente de terra. Dias depois, ao serem peneirados os últimos blocos, foi que constatamos a presença ainda de algumas radicelas. Nos estudos posteriores em outros solos, esta falta foi sanada verificando-se a ausência de radicelas nos blocos depois de peneirados, para então dar a escavação por terminada.

A distribuição do sistema radicular do cafeeiro na terra roxa misturada de Campinas é ideal, conforme notamos no gráfico I e na fig. IV. A quantidade de radicelas é grande e a sua distribuição excelente, pois que não há acúmulo de raízes na superfície, mas estão elas mais ou menos uniformemente distribuídas até às camadas mais profundas. Tal distribuição explica a maior resistência à sềca, dos cafeeiros em Campinas. 
De fato, no auge das grandes sêcas temos observado que, enquanto em outras regiões, principalmente em Ribeirão Preto, os cafeeiros perdem a quase totalidade de suas fôlhas, em Campinas êles conservam boa percentagem delas $\left(^{*}\right)$. Tendo grande número de radicelas a profundidades além de 2 metros, o cafeeiro encontra ainda água suficiente, mesmo nas épocas sêcas.

Da não existêneia de um acúmulo de radicelas nas camadas superficiais podemos concluir que os tratos culturais, principalmente quando feitos por meio de máquinas, mesmo sendo profundos, pouco devem prejudicar a árvore, já que as radicelas cortadas são em pequeno número em relação ao total.

Com tal distribuição de raízes, as adubações dos cafeeiros em Campinas podem e devem mesmo ser profundas a fim de serem melhor aproveitadas. Os adubos fàcilmente lavâveis, tais como os nitratos, são melhor aproveitados neste solo, pois que para escaparem à absorção pelas raízes precisariam ser levados pela água a profundidades maiores que 2,5 metros.

Também podemos observar que não há entrelaçamento demasiado entre as raízes dos cafeeiros vizinhos o que indica que o espaçamento empregado é bom. Quanto a isto, notamos que o espaçamento é bem variável entre as quatro plantas estudadas, fato aliás feliz, pois que nos permite observar o efeito de três espaçamentos sôbre o sistema radicular. Parece-nos que o espaçamento existente entre as duas plantas do meio é o melhor para êste tipo de solo, proporcionando uma exploração homogênea do solo sem que haja grande entrelaçamento entre as raízes das plantas. Este espaçamento é de 3,0 metros, de centro a centro das covas. $O$ espaçamento existente entre as duas plantas da esquerda, de $3,90 \mathrm{~m}$, parece ser um pouco demasiado, pois o solo entre uma e outra não é bem explorado como se conclui da pequena densidade de raízes aí existente.

A razão de uma tão boa distribuição do sistema radicular dos cafeeiros de Campinas vamos eneontrar ao examinar nos gráficos II e III, os diagramas volumétricos físico e químico do solo daquela localidade. Vemos que o solo é homogêneo de alto a baixo do perfil; bastante poroso até às camadas mais profundas. Sua riqueza total decresce muito pouco com a profundidade. Das plantas estudadas, duas têm quatro pés por cova e outras duas três pés por cova, mas não se nota neste ponto influência sôbre o sistema radicular, nem mesmo nos pesos totais de raízes, que são os seguintes: planta $n .^{\circ} 1=8,8 \mathrm{Kg}$; planta . $^{\circ} 2=6,5 \mathrm{Kg}$; planta n. ${ }^{\circ} 3=11,0 \mathrm{Kg}$ e planta $\mathrm{n} .^{\circ} 4=9,5 \mathrm{Kg}$, dando uma média de $8,9 \mathrm{Kg}$ para cada sistema radicular.

(*) A superfície folhar média, de um cafeeiro em Campinas, na estação chuvosa, é de cêrca de 32 metros quadrados, ao passo que na estação sêca é de 12 metros quadrados. (Dados ainda não publicados). 


\section{2) Sistema radicular do cafeeiro na terra roxa legítima de Ribeirão Preto}

O sistema radicular neste tipo de solo está representado no gráfico IV e fig. V. Neste solo sòmente três plantas em linha foram estudadas devido ao fato de (por ser o talhão pequeno) não têrmos encontrado 4 plantas perfeitamente alinhadas e na mesma linha de nível, condições ideais para a execução do presente trabalho.

Vemos que a grande maioria de radicelas está acumulada nas camadas mais superficiais do solo, até à profundidade de 0,30 metros, sendo que apenas poucas radicelas vão além de 1,0 metro. A profundidade máxima alcançada pelas raízes é de 2,40 metros, porém apenas por algumas radicelas. Durante as épocas sêcas os cafezais de Ribeirão Preto perdem, como já dissemos atrás, quase tôda a sua folhagem ficando "em varas", como se diz nos meios agrários.

Podemos agora explicar êste fato como sendo consequência de dois fatôres : a) - porque, tendo os cafeeiros um sistema radicular muito superficial, não podem retirar água eficientemente além da profundidade de 1,0 metro, ou pouco mais ; b) - porque, aliado a êste grande inconveniente e agravando-o ainda mais, está o fato já conhecido de ser a terra roxa de Ribeirão Preto excessivamente porosa e ter capacidade diminuta de reter âgua, o que bem se vê no diagrama volumétrico físico do perfil daquele solo representado no gráfico V. Poucos dias depois de uma chuva abundante, já aquêle solo perde das camadas superifciais quase tôda a água disponível às plantas.

Os tratos culturais, principalmente mecânicos, devem prejudicar bastante os cafeeiros neste solo, desde que, em consequência do seu acúmulo nas camadas superficiais, a percentagem de radicelas cortadas é considerável. Parece-nos que durante o crescimento e formação dos cafeeiros seria vantajosa a aplicação dos adubos a uma maior profundidade a fim de estimular o crescimento das raízes nas camadas mais profundas. Êsses adubos deveriam, porém, ser de decomposição lenta, para evitar que fôssem levados ràpidamente pela água a profundidades fora do alcance das raízes.

Se tal prática pode ser ou não eficiente em plantas já há muito formadas, sòmente experiências instaladas para êsse fim poderiam nos informar, depois de vários anos.

Quanto ao espaçamento, o de 3,60 metros existente entre as duas plantas da esquerda parece ser o melhor, já que não há forte entrelaçamento das raízes. Considerando, porém, que a grande maioria das raízes está nas camadas superficiais e que, portanto, sòmente essas camadas são intensamente exploradas, talvez o espaçamento ideal para êste tipo de solo seja ainda maior que $3,60 \mathrm{~m}$. Uma das plantas estudardas tem 2 pés por cova, ao passo que as outras duas têm três, mas não se nota qualquer diferença no sistema radicular que possa ser atribuída a êsse fato. 
Os pesos dos sistemas radiculares das plantas estudadas foram : planta n. ${ }^{\circ} 1: 13,2 \mathrm{Kg}$; planta $\mathrm{n} .^{\circ} \cdot 2: 15,9 \mathrm{Kg}$; planta $\mathrm{n}^{\circ} 3: 12,4 \mathrm{Kg}$, dando uma média de $13,8 \mathrm{Kg}$ por planta.

A péssima distribuição do sistema radicular dos cafeeiros de Ribeirão Preto é explicada pelo diagrama volumétrico químico do perfil do solo do local onde foi feito o estudo do sistema radicular, representado no gráfico VI. Vemos, comparando as áreas correspondentes a $\mathrm{Ca}+\mathrm{Mg}$ e azôto, que a sua riqueza total decresce muito bruscamente com a profundidade.

Devemos lembrar ainda que os clementos que se acham nas camadas mais profundas com menor aeração, menor flora microbiana, etc., são mais difìcilmente aproveitáveis pelas plantas, o que mais agrava ainda aquêle inconveniente.

\section{3) Sistema radicular do cafeeiro no solo bauru superior de Pindorama}

No gráfico VII e fig. VI vemos que o sistema radicular do cafeeiro nas terras da Estação Experimental de Pindorama, embora não tão bom quanto nas de Campinas, é bastante superior ao de Ribeirão Preto. A maior parte das raízes está nos primeiros $0,80 \mathrm{~m}$ de solo, mas ainda há boa quantidade de radicelas até cêrea de $1,30 \mathrm{~m} . \Lambda$ profundidade máxima atingida por algumas radicelas foi de $1,90 \mathrm{~m}$.

$\Lambda$ julgar pelo sistema radicular, os cafeeiros de Pindorama estão entre os de Campinas e os de Ribeirão Preto, quanto à resistência à sêca. $O$ mesmo se pode dizer quanto aos efeitos dos tratos culturais e adubação. Quanto ao espaçamento, que varia também nas plantas estudadas, ie 3,0 a 3,30 m, êste último parece ser o melhor e talvez melhor seria ainda um espaçamento um pouco maior a fim de causar menor entrelaçamento de raízes nas camadas superficiais. Entre as plantas estudadas, uma tem dois pés por cova, outra tem quatro e outras duas têm cinco e podemos observar que isto não influi sôbre o desenvolvimento do sistema radicular.

Foram os seguintes os pesos dos sistemas radieulares das plantas estudadas : planta $.^{\circ} 1: 7,9 \mathrm{Kg}$ : planta $n .^{\circ} 2: 7,3 \mathrm{Kg}$; planta $n .^{\circ} 4: 8,2 \mathrm{Kg}$, dando-nos uma média de $7,7 \mathrm{Kg}$ por planta.

Também podemos explicar a distribuição das raízes do cafeeiro no solo de Pindorama pelo diagrama volumétrico físico do perfil daquele solo o que vemos no gráfico VIII. A sua porosidade decresce muito nas camadas mais profundas, a partir de cêrca de $0,80 \mathrm{~m}$, e aumenta bastante o teor em argila. Isto produziu um pequeno adensamento de raízes nas camadas mais rasas. 


\section{4) Sistema radicular do cafeeiro na terra "massapé-salmourão" de Ibiti, município de Amparo}

0 gráfico $\mathrm{X}$ e a fig. VII mostram o sistema radicular dos cafeeiros estudados na terra massapé-salmourão da Estação Experimental de Ibiti, município de Amparo.

Salta à vista, ao primeiro exame, a irregularidade na distribuição das raízes. Isto ocorre em virtude de não ser êste solo tão homogêneo quanto aquêles añteriormente estudados. A presença de pedras e veios de pedregulhos, comuns neste tipo de solo, obriga as raízes a se desenvolverem de maneira irregular. Notamos também que a camada superficial varia grandemente de espessura e isto não pode ser evitado por ser o solo bastante montanhoso e porque as plantas estavam em níveis diferentes.

A distribuição das raízes neste solo não é má, embora irregular e com pequeno adensamento de raízes finas nas camadas mais superficiais. A profundidade mâxima atingida pelas raízes é de $2,50 \mathrm{~m}$, na primeira planta à esquerda, e de 3,10 m na última planta, à direita. Nesta, porém, apenas a insignificante quantidade de $0,09 \mathrm{gr}$ de radicelas ultrapassa a profundidade de $2,50 \mathrm{~m}$.' Boa quantidade de radicelas atinge profundidades próximas de $2,0 \mathrm{~m}$, o que é uma garantia para a planta nas estações sêcas.

Enquanto nos sistemas radiculares atrás estudados as raízes que se aprofundam são radicelas muito finas, no de Ibiti, raízes de maior diâmetro vão até profundidades maiores.

Isto é devido ao fato de ser o solo dêste último lugar mais compacto e menos poroso do que os anteriormente considerados e é também uma indicação de ter êste solo mais âgurua do que aquêles, nas camadas mais profundas.

Os tratos culturais devem ser feitos com cuidado, já que a quantidade de radicelas existentes nas camadas superficiais é uma boa percentagem do total, fato que se observa bem no gráfico $\mathbf{X}$ e fig. VII.

Seria interessante, também neste solo, uma experiêneia de adubação a profundidades maiores a fim de forçar o desenvolvimento um pouco mais profundo das radicelas superficiais. Quanto ao espaçamento, a julgar pelas árvores estudadas, não deve ser menor de $3,60 \mathrm{~m}$, para se evitar grande concorrência entre árvores vizinhas.

Examinando nos gráficos XI e XII os diagramas volumétricos do perfil do solo de Ibiti, vamos encontrar explicação para a distribuição de raízes encontrada naquele solo. $\mathrm{O}$ pequeno adensamento de raízes finas nas cámadas mais superficiais é explicável pela maior riqneza daquelas camadas. Comơ vemos na fig. VII e atrâs dissemos, neste solo, raízes de maior diâmetro vão até maiores profundidades. É uma reação comum das raízes à falta de bastante ar, o fato de se desenvolverem mais no seu diâmetro e se subdividirem menos. O diagrama volumétrico físico do solo 
de Ibiti, representado no gráfico XI, nos dá a prova disto, pois vemos que aquêle solo é muito pouco poroso, encerrando muito pouco ar nas camadas mais profundas.

Os pesos dos sistemas radiculares das plantas estudadas em Ibiti foram : planta $n .^{\circ} 1=11,8 \mathrm{Kg}$; planta . $^{\circ} 2=14,9 \mathrm{Kg}$; planta n. ${ }^{\circ} 3=16,8 \mathrm{Kg}$ e planta $n^{\circ} 4=23,4 \mathrm{Kg}$, o que dá uma média de $16,7 \mathrm{Kg}$ por planta.

\section{5) Sistema radicular dos cafeeiros na terra roxa misturada de Jaú}

O gráfico XIII e a fig. VIII mostram o sistema radicular dos cafeeiros estudados em Jaú.

Como vemos, é bastante semelhante ao sistema radicular das plantas de Ibiti, porém mais uniformemente desenvolvido em consequência de ser o solo homogêneo. Se bem que mais raso do que o das plantas em Ibiti, o sistema radicular das plantas de Jaú não representa acúmulo de radicelas nas camadas superficiais, o que é de grande vantagem, como já frizamos várias vêzes, com relação à resistência à sêca, e aos tratos culturais.

A profundidade máxĩma atingida pelas radicelas é de $2,20 \mathrm{~m}$.

O espaçamento, que nas plantas estudadas varia de 3,30 a 3,60 , parece ser muito bom, pois que permite uma boa exploração do solo sem que haja grande entrelaçamento entre as raízes das plantas vizinhas.

Neste solo há maior quantidade de raízes finas nas camadas mais profundas do que no de Ibiti e vemos pelo diagrama volumétrico físico, no gráfico XIV, que êle é de fato mais poroso, encerrando mais ar e também vemos pelo gráfico $X V$ que a sua riqueza química total decresce menos com a profundidade do que no solo de Ibiti.

Os sistemas radiculares das plantas estudadas tinham o seguinte pêso: planta $n .^{\circ} 1=16,4 \mathrm{Kg}$; planta $n . .^{\circ} 2=6,0 \mathrm{Kg} ;$ planta $n .^{\circ} 3=19,2 \mathrm{Kg}$ e planta n. $^{\circ} 4: 12,1 \mathrm{Kg}$, sendo o pêso médio de $13,4 \mathrm{Kg}$.

Vemos que o pêso do sistema radicular da planta número 2 é bastante diferente dos outros. Talvez por alguma razão fôsse êle muito assimétrico.

\section{CONCLUSÕES GERAIS}

Não podemos falar em um sistema radicular típico do cafeeiro, mas sim do seu sistema radicular em um determinado tipo de solo, pois vimos o quanto as propriedades físicas e químicas do solo modificam a distribuição das raízes. Mesmo em solos idênticos, condições locais podem modificar a configuração do sistema radicular.

A única afirmativa que podemos generalizar é a de que as raízes primárias do cafeeiro não vão além de $0,5 \mathrm{~m}$ de profundidade, não sendo 
pivotante o sistema radicular desta planta, nas condições atuais de cultura, em que a formação das mudas sofre vários transplantes. Não sabemos se um cafeeiro plantado de semente, no local definitivo, teria um sistema radicular idêntico aos por nós encontrados. Talvez, se possível na prática, a semeação no local definitivo produzisse plantas com um sistema radicular melhor e mais profundo.

A melhor distribuição do sistema radicular encontrada foi no solo de Campinas, que é de terra roxa misturada.

Seguem-se, em ordem decrescente, os sistemas radiculares dos cafeeiros de: Pindorama, sôbre solo bauru superior; Ibiti, sôbre solo massapísalmourão; Jaú sôbre terra-roxa misturada e Ribeirão Preto, sôbre terraroxa legítima, sendo que neste último solo os cafeeiros exibem um péssimo sistema radicular.

A máxima profundidade a que atingiram as raízes foi também na terra-roxa misturada de Campinas, onde ultrapassaram 2,50 m, atingindo, provàvelmente, $3,0 \mathrm{~m}$.

O sistema radicular mais raso foi encontrado no solo bauru superior de Pindorama, onde as raízes alcançaram sòmente $1,90 \mathrm{~m}$ de profundidade, sendo, porém, boa a sua distribuição.

Dos nossos esturtos, podemos concluir também que não existe um espaçamento ótimo para o cafeeiro, mas sim que êle deve variar com o tipo de solo em que cresce aquela planta. Assim, quanto ao sistema radicular, os seguintes espaçamentos parecem ser os melhores para os respectivos tipos de solo: $3,0 \mathrm{~m}$ para a terra-roxa misturada de Campinas; 3,60 m para a terra-roxa legítima de Ribeirão Preto, terra massapésalmourão de Amparo e roxa misturada de Jaú, e 3,50 m para o solo bauru superior de Pindorama.

Os tratos culturais nos cafezais sôbre terra-roxa misturada idêntica à de Campinas, podem ser profundos, sem inconvenientes para os cafeeiros que têm suas raizes bem profundas nesse tipo de solo. Já na terra-roxa legítima de Ribeirão Preto aquêles tratos devem ser rasos, a fim de não prejudicarem grande percentagem de raízes absorventes, que naquele solo são superficiais.

Seriam aconselhâveis, principalmente para o solo de Ribeirão Preto, experiências no sentido de estimular o desenvolvimento mais profundo das raízes do cafeeiro, especialmente em cafezais em formação, tais como aplicação de matéria orgânica e adubos pouco solúveis, a uma profundidade maior, abertura de sulcos em tôrno das plantas, etc.

\section{AGRADECTMENTOS}

Os autores expressam aqui os seus sinceros agradecimentos ao $\mathrm{Sr}$. Luiz O. T. Mendes, a quem devem, na sua maior parte, a elaboração do método para o cálculo do pêso total do sistema radicular, ao Sr. J. E. de 
Paiva Neto, chefe da Seccão de Agrogeologia, por se ter encarregado dos estudos referentes aos solos e ao Sr. J. Castro Mendes, pela execução dos trabalhosos gráficos dos sistemas radiculares.

\section{S U M M A R Y}

A new method for the study of the reot system of the coffee plant Coffea arabica L. is deseribed. The method consists in exeavating a ditch along a row of four plants, $15 \mathrm{~cm}$ apart from the trunks. Blocks of soil $30 \mathrm{~cm}$ square and varying thickness, depending on the depth from which they were taken, were removed so as to include a complete cross section of the root system. The first three layers were $10 \mathrm{~cm}$ thick; the next two layers, $20 \mathrm{~cm}$; the remaining layers (variable in number), $30 \mathrm{~cm}$ thick.

The roots from each block were washed, air dried and weighed. The data obtained were used to draw the exearation maps as represented in graphics, I, IV, VII, X and XIII. On theses maps each dot represents $0.1 \mathrm{~g}$ of roots.

A formula is given to estimate the weight of the whole root system, from the data thus obtained.

The method just described was used to study the root system of the coffee tree in four different types of soil of the State of São Paulo, Brazil. It is pointed out that the study of the root distribution based on weight alone might lead one to erroneous eonclusions, sinee the first layers contain heavy non-absorbing roots whereas many active roots, light in weight, are loeated in deeper layers.

A much better idea about the root distribution in the soil was obtained by drawing the excavation map on a black eloth in true seale, and then spreading the roots removed from each block soil inside the corresponding place in the map. The pictures of this arrangement are reproduced in fig. IV, V, VI, VII and VIII.

The best root distribution was found in the soil "terra-roxa misturada" in the Campinas county (fig. IV). In this soil the roots extend beyond $2.5 \mathrm{~m}$ depth and are very well distributed through the soil.

The poorest root distribution was found in the soil "terra-roxa legitima" in the Ribeirão Preto county (fig. V). In this soil the roots are mostly confined to the superficial layers.

A study of the soil profiles where the trees were growing offered an explanation for the configuration of the root systems as obtained by the last method. Diagrams of the profiles are given in the text.

\section{LITERATURA CITADA}

1. Beckley, V. A. Observations of coffee in Kenya. Pt. I, Chlorosis and die-back in coffee. Empire Jour. Exp. Agric. 3: 203-209. 1935.

2. Dafert, F. W. e Toledo Braga. Sôbre as substâncias minerais do eafeeiro. B. Relação de pêso das partes singulares do eafeeiro. Relatório Secret. Agric, Com. Obr. Publ. São Paulo, 1892: 20-23. 1917.

3. Guiseafré-Arrilaga, J. and. L. A. Gomez. Studies of the root system of Coffea arabica L. I. Environment conditions affecting the distribution of coffee roots in Coloso clay. Jour. Agric. Univ. Puerto Rico 22: 227-262. 1938.

4. Guiscafré-Arrilaga, J. and L. A. Gomez. Studies of the root sistem of Coffea arabica L. III. Growth and distribution in Catalina elay soil. Jour. Dept. Agric. Puerte Rico. 24: 109-117. 1940. 
5. Guiscafré-Arrilaga, J. and L. A. Gomez. Studies of the root system of Coffea arabica L. III. Growth and distribuition of roots of 21-old trees in Catalina clay soil. Jour. Agrie. Cniv. Puerto Rico. 26: 34-39. 1942.

6. Nutman, F. J. The root-system of Coffea arabica L. I. Root_system in typical soils of British East Africa. Emp. Jour. Exp. Agric. 1: 271-284. 1933.

7. Nutman, F. J. The root-system of Coffea arabica IT. The effect of somme soil conditions in modifying the normal root-system. Emp. Agric. 1: 285.296. 1933.

8. Nutman, F. J. The root-system of Coffea arabica III. The spacial distribution of the absorbing area of the root. Emp. Jour. Agric. 2: 293-302. 1934.

9. Trench, A. D. Preliminary observations on coffec roots in Kenya. Kenya Dept. Agric. Bull. n. 2 pp 1-10. 1934. 
INSTITUTO AGRONOAMICO - SECCCAO DE SOLOS

PERFIL 384

MUNICIPIO: Campinas LOCALIDADE: fazenda sto Eliza

DIAGRAMA VOLUMEETRICO FISICO

ALTITUDE: $680 \mathrm{~m}$

ZONA GEOLOGICA: Glacial

ROCHA MATER - Diabase + rochas permo-carboniferas preexistentes

VEGETACAO: Cafesa

TIPO DO SOLO: Terra Roxa Misturadá

PERMEAB, om mm de chuva por hora:

Permeab. $\mathrm{mm} /$ hord $A, A, B$

COLHEITA FISICAMENTE POSSIVEL (Sekera):

LOCAL SOMBREADO POR UM RIPADO

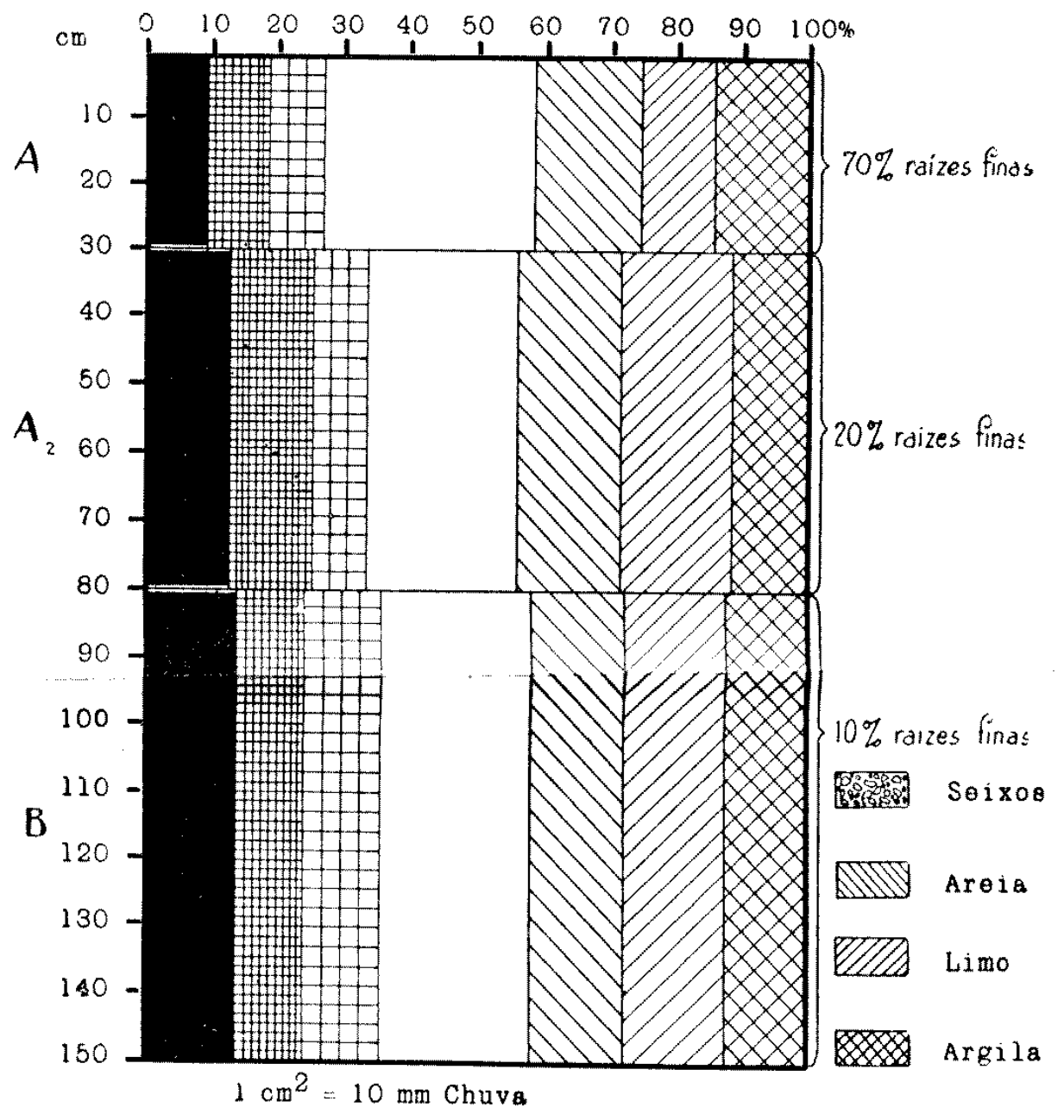

Migroscopicidade

Umiaade equivalente

Água capilar máxima

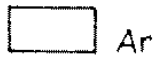




\section{INSTITUTO AGRONÔMICO do ESTADO DE S.PAULO}

\section{SECÇÃO DE SOLOS \\ PERFIL N: 384 \\ DIAGRAMA VOLUMÉTRICO QUÍMICO}

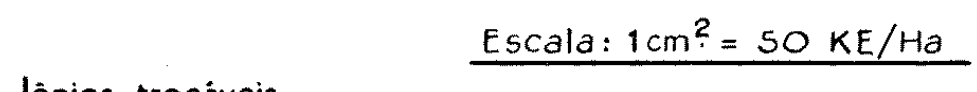

lônios totain

lônios trocáveis
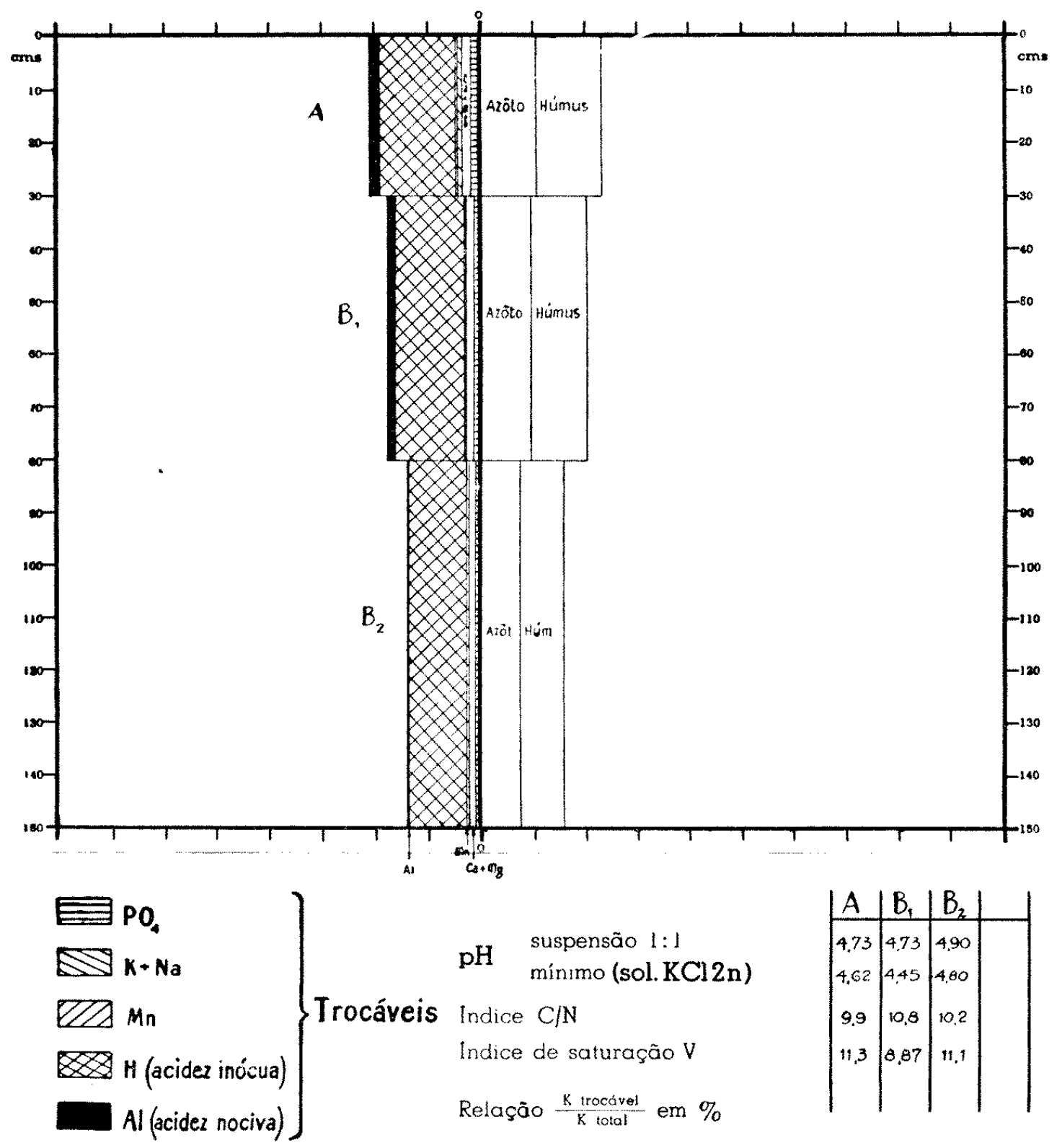


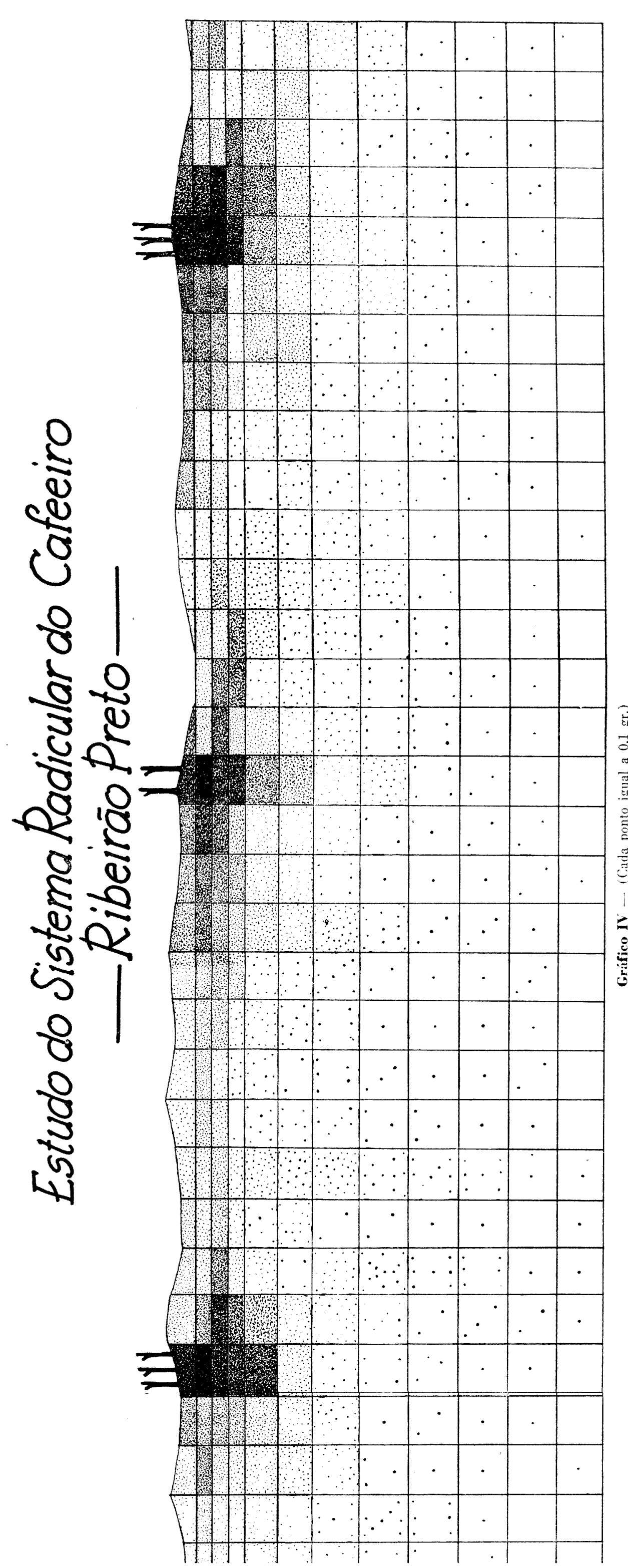


Instituto Agronômico

Seç̧ão de Agrogeologia

PERFIL 401

MUNICIPIO: Ribeirão Preto LOCALIDADE: Est. Experimental

\section{DIAGRAMTA VOLUMTÉTRICO FÍSICO}

ALTITUDE: $687.3 \mathrm{~m}$

ZONA GEOLÓGICA: Botucatú

ROCHA MAIER: Diabásio

VEGETACÄO: Cafesal

TIPO DO SOLO: Terra roxa legitima

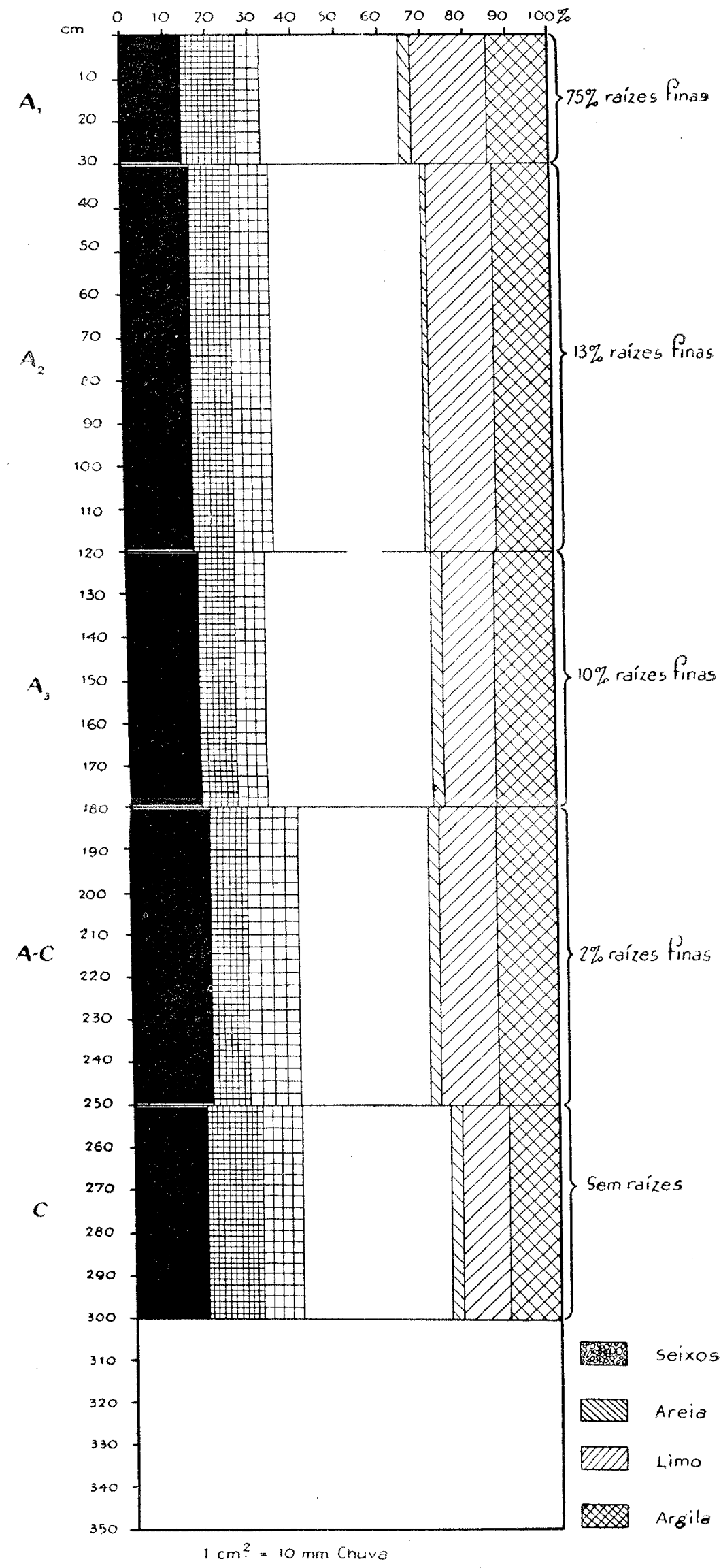

Higroscopicidade umidade equivalente

DI Agua capilar máxima 
Instituto Agronomico

Seçáo de Agrogeologia

PERFIL 401

\section{DIAGRAMA VOLUMÉTRICO QUIMICO}

\section{Escala: $1 \mathrm{~cm}^{2}=50 \mathrm{KE} / \mathrm{Ha}$}
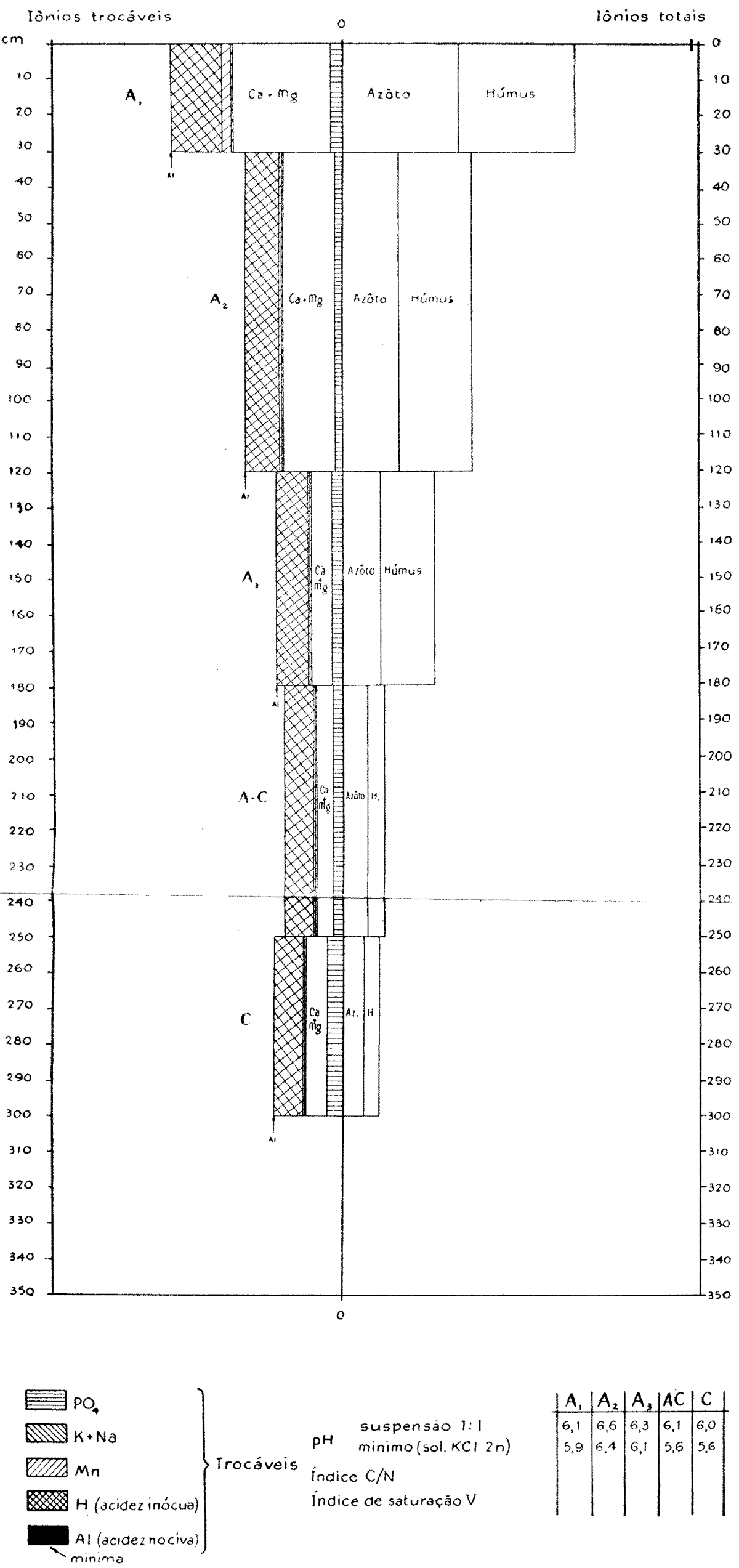


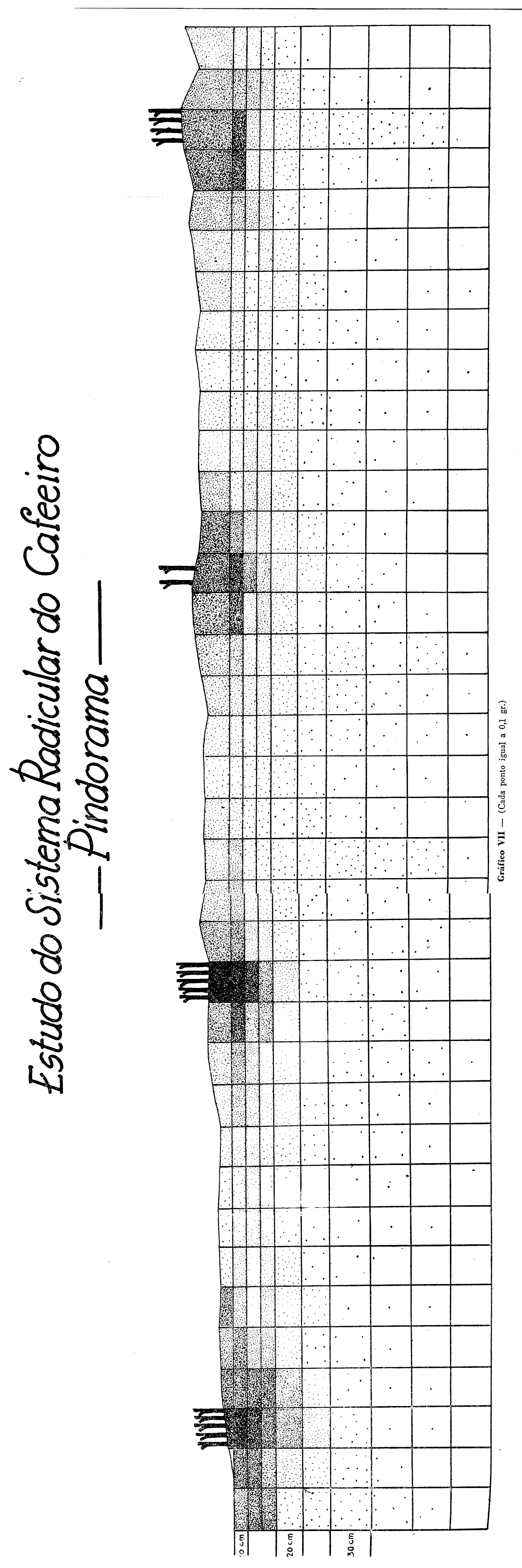




\section{INSTITUTO AGRONOMICO - SECCAAO DE SOLOS}

\section{PERFIL 498}

MUNICIPIO : Pindorama LOCALIDADE : Est. Experimental

\section{DIAGRAMA VOLUMIÉTRICO FISICO}

\section{ALTITUDE:}

ZONA GEOLOGICA: Baurú superior

ROCHA MATER: Arenito Cretáceo

VEGETAQȦO: Cafezal

TIPO DO SOLO: Arenoso

PERMEAB. em mm de chuva por hora:

COLHEITA FISICAMENTE POSSTVEL (Sekera):

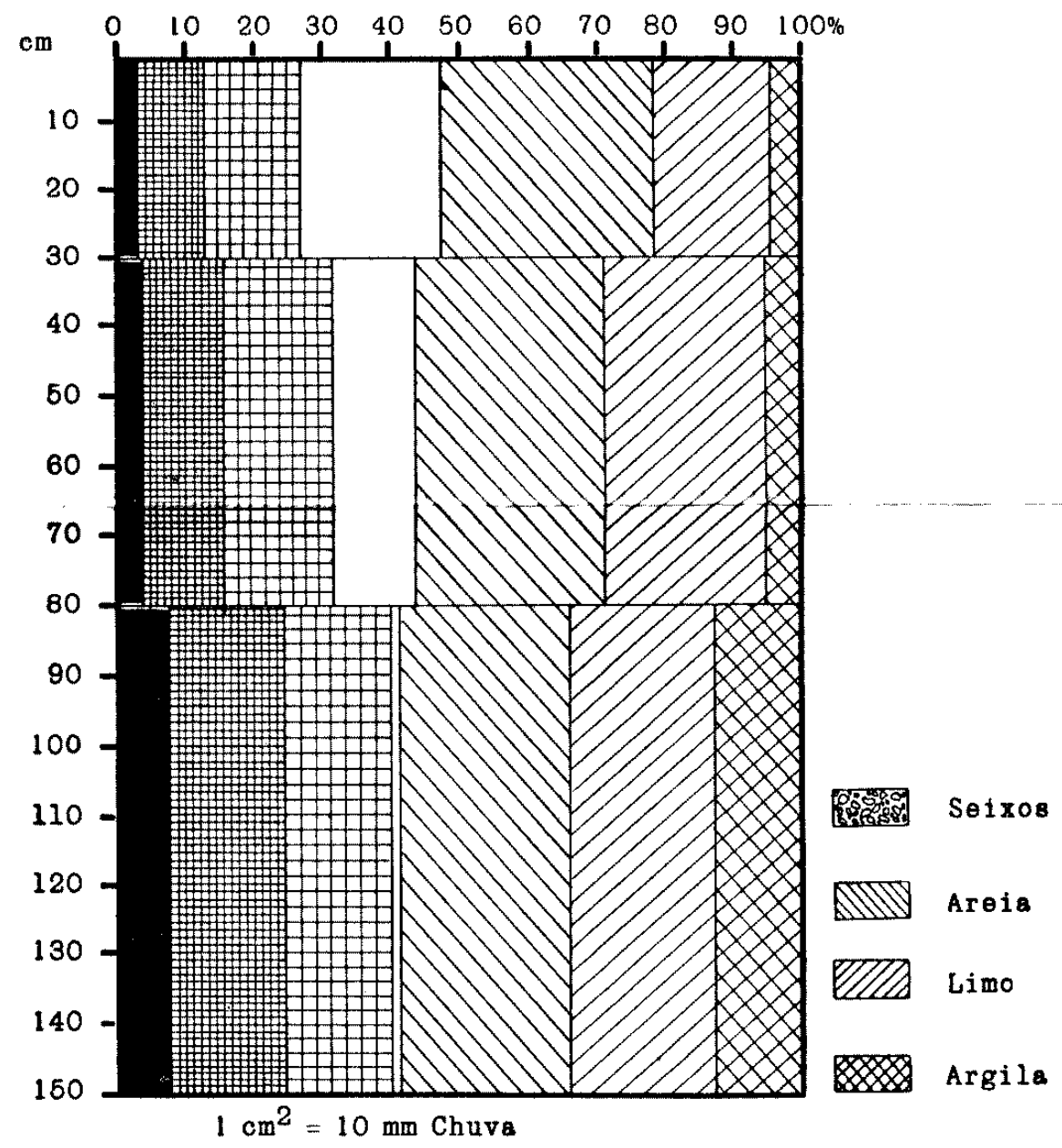

Highroscopicıdade

田的 đ̧ua capilar máxima

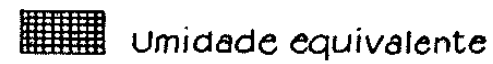
Ar 


\section{INSTITUTO AGRONÔMICO de ESTADO DE S.PAULO}

\section{SECÇȦO DE SOLOS \\ PERFIL N: 498 \\ DIAGRAMA VOLUMÉTRICO QUÍMICO}

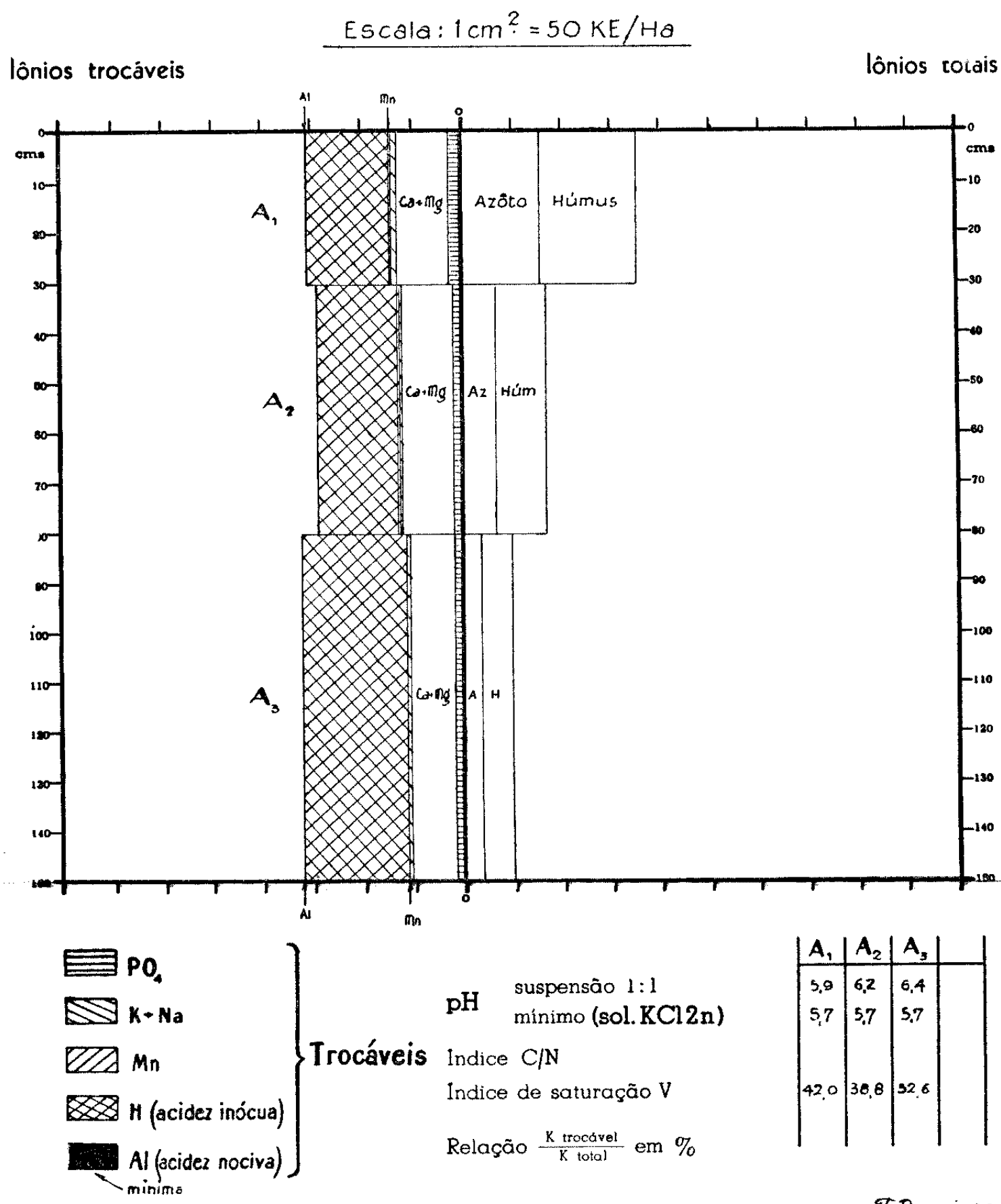

F, Domingo.

Gráfico IX 



\title{
INSTITUTO AGRONOMICO - SECCAAO DE SOLOS
}

\author{
PERTIL 493
}

MUNICIPIO: Amparo

LOCALIDADE : ibiti - Est. Experimentol

\section{DIAGRAMA VOLUMIETRICO FISICO}

ALTITUDE: $750 \mathrm{~m}$

ZONA GEOLOGICA: Arqueano

ROCHA MATER: Gneiss.

VEGETAQ̨ÃO: Cafezal

TIPO DO SOLO: Massapés - Salmourào

PERMEAB. em mm de chuva por hora:

COLHEITA FISICAMENTE POSSIVEL (Sekera):

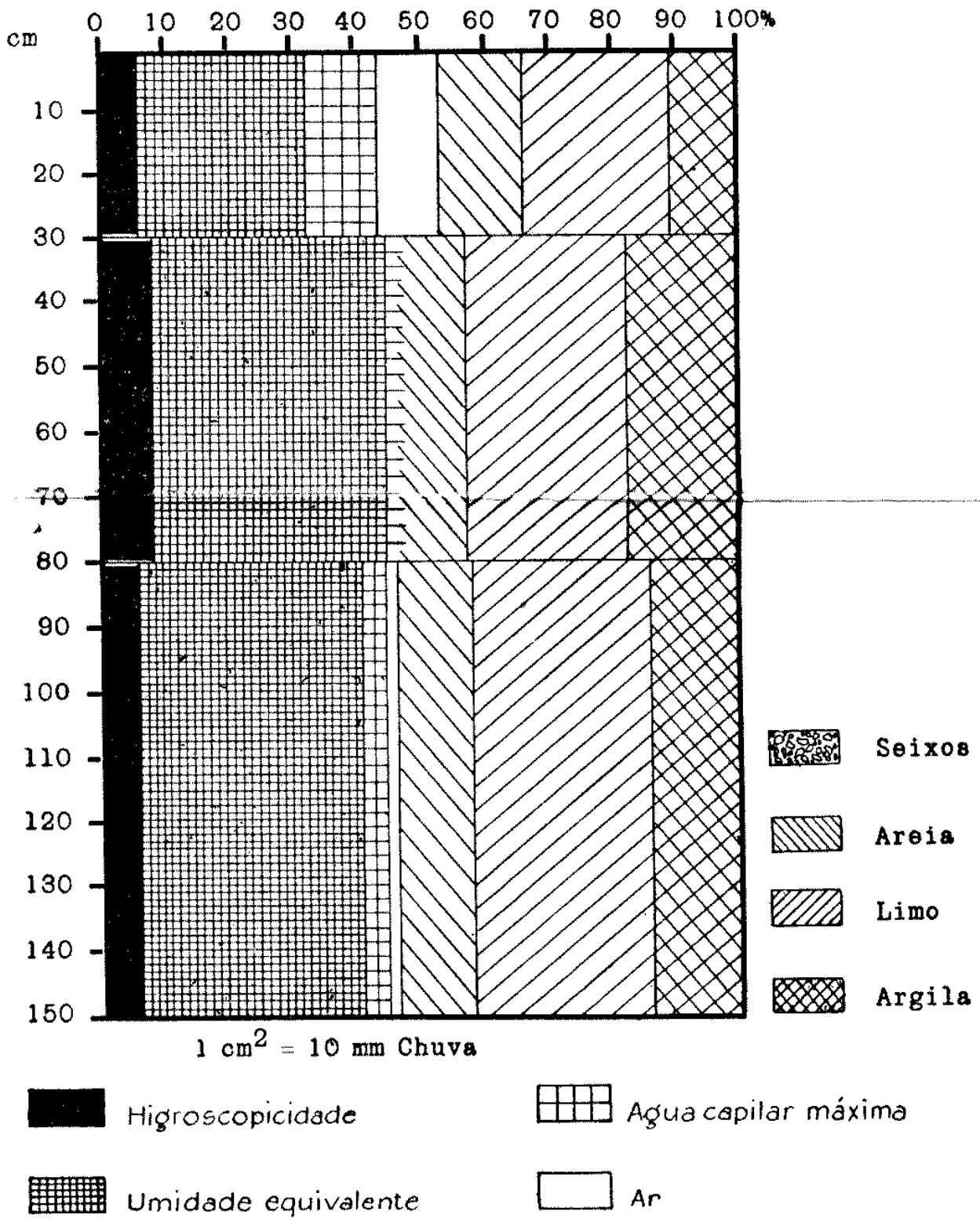




\section{INSTITUTO AGRONÔMICO do ESTADO DE S.PAULO}

\section{SECÇÃO DE S.OLOS \\ PERFIL N: 493 \\ DIAGRAMA VOLUMÉTRICO QUÍMICO}

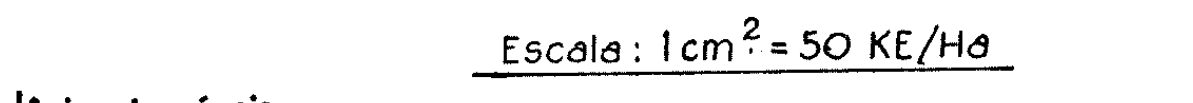

lônios totais

lónios trocáveis

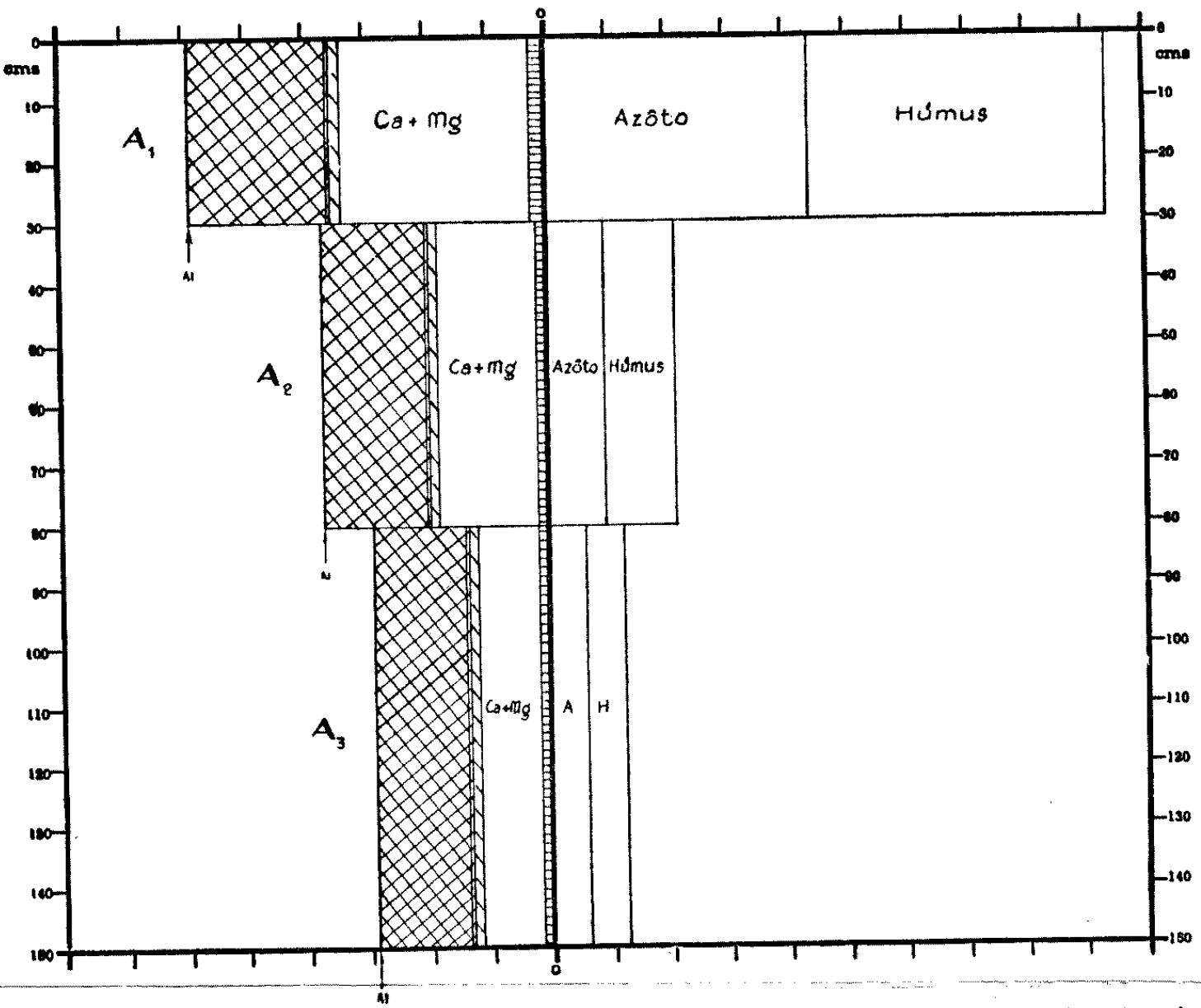

\begin{tabular}{|c|c|c|c|c|c|}
\hline & & & $A_{1}$ & $A_{2}$ & $A_{3}$ \\
\hline$\Longrightarrow \mathrm{PO}_{4}$ & & suspensõo $1: 1$ & 6.4 & 6.8 & 6,8 \\
\hline$\$ 8 k+N a$ & & $\mathrm{pH}$ mínimo (sol. $\mathrm{KCl} 2 \mathrm{n}$ ) & 5.7 & 5.7 & 5.7 \\
\hline$\square 7 M_{n}$ & Trocáveis & Indice $\mathrm{C} / \mathrm{N}$ & & & \\
\hline H (acidez inócua) & & Indice de saturação V & 59,6 & 51,5 & 51.4 \\
\hline Al (acidez nociva) & & Relação $\frac{\mathrm{K} \text { trocávol }}{\mathrm{K} \text { total }} \mathrm{em} \%$ & & & Dom \\
\hline
\end{tabular}

Gráfico XII 


\section{INSTITUTO AGRONOOMICO - SECCAAO DE SOLOS}

\section{PERFIL 497}

MUNICIPIO : Jau

LOCALIDADE : Est. Experimental

\section{DIAGRAMIA VOLUMETTRICO FISICO}

ALT ITUDE :

ZONA GEOLOGICA: Botucatú

ROCHA MATER: Diabasio + arenito Botucatu

VEGETAÇÀO. Cafezal velho

TIPO DO SOLO: Terra roxa misturada

PERMEAB, om mm de chuva por hora:

COLHEITA FISICAMENTE POSSTVEL (Sekera):

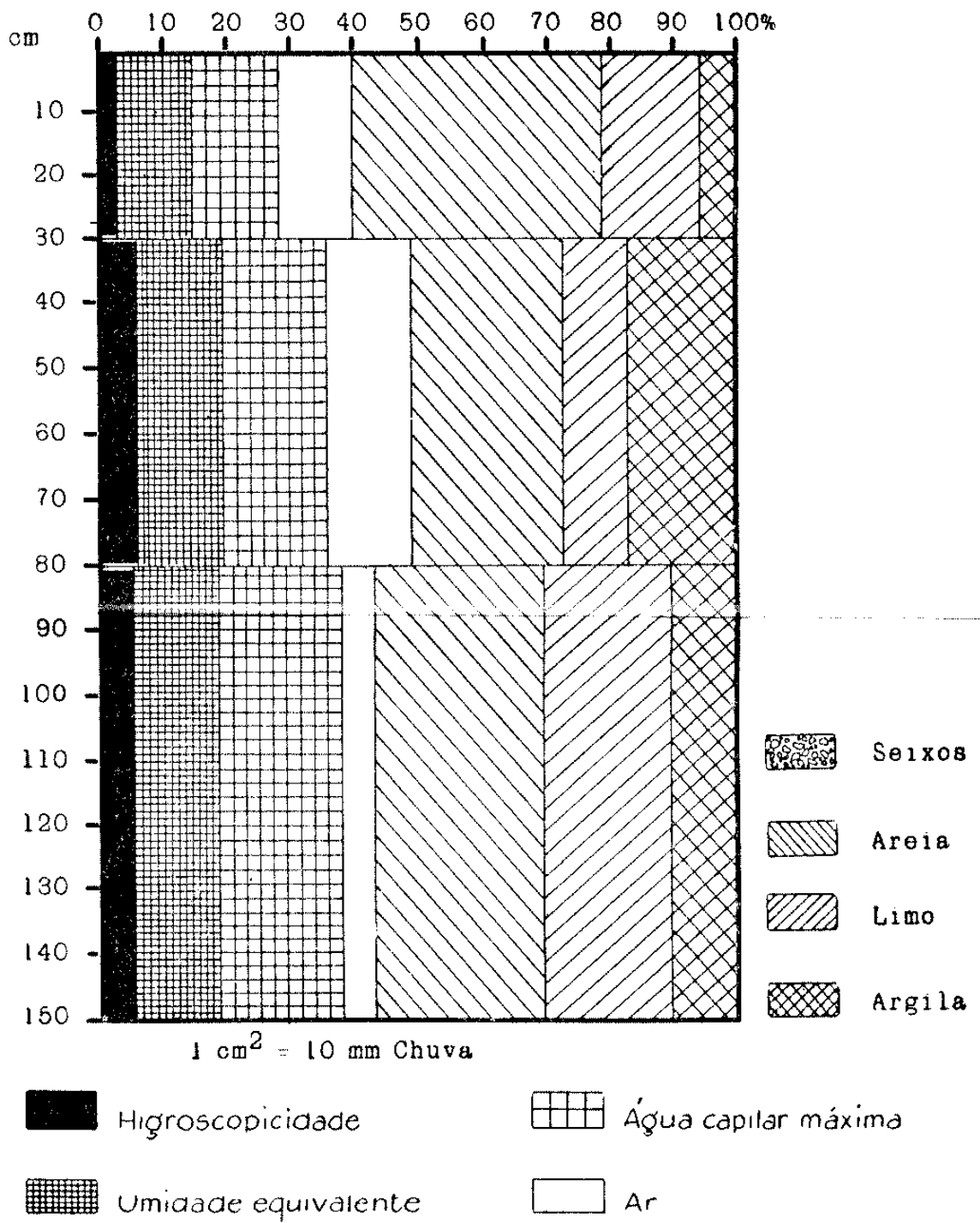




\section{INSTITUTO AGRONÔMICO do ESTADO DE S.PAULO}

SECÇÃo DE SOLOS

PERFIL N: 497

DIAGRAMA VOLUMÉTRICO QUÍMICO

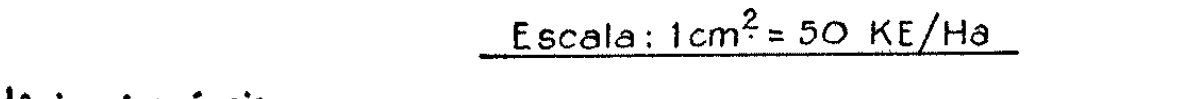

lônios totais

lônios trocáveis

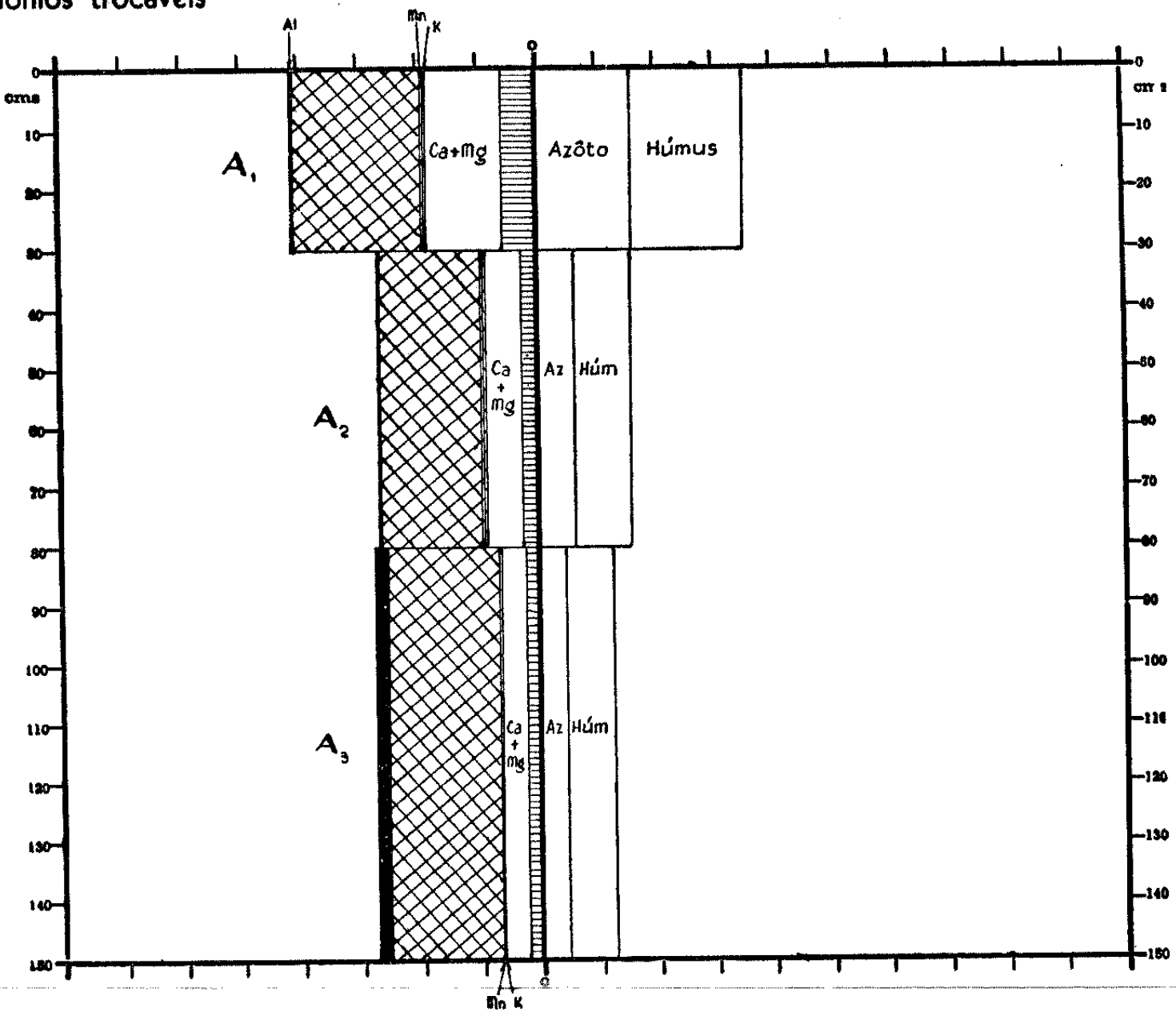

\begin{tabular}{|c|c|c|c|c|c|}
\hline 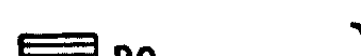 & & & $A, \mid$ & $A_{2}$ & $A_{3}$ \\
\hline$\Longrightarrow \mathrm{PO}_{4}$ & & suspensão $1: 1$ & 5.7 & 5,5 & 4,9 \\
\hline$S \mathrm{~K}+\mathrm{Na}$ & & mínimo (sol. KCl2n) & 52 & 5.4 & 5,2 \\
\hline$\Delta M_{n}$ & Trocáveis & Indice $\mathrm{C} / \mathrm{N}$ & & & \\
\hline H (acidez inócua) & & Indice de saturação V & 22.5 & 27.4 & 196 \\
\hline Al (acidez nociva) & & Relação $\frac{\mathrm{K} \text { troodval }}{\mathrm{K} \text { total }}$ em \% & & & \\
\hline
\end{tabular}

Gráfico XV 


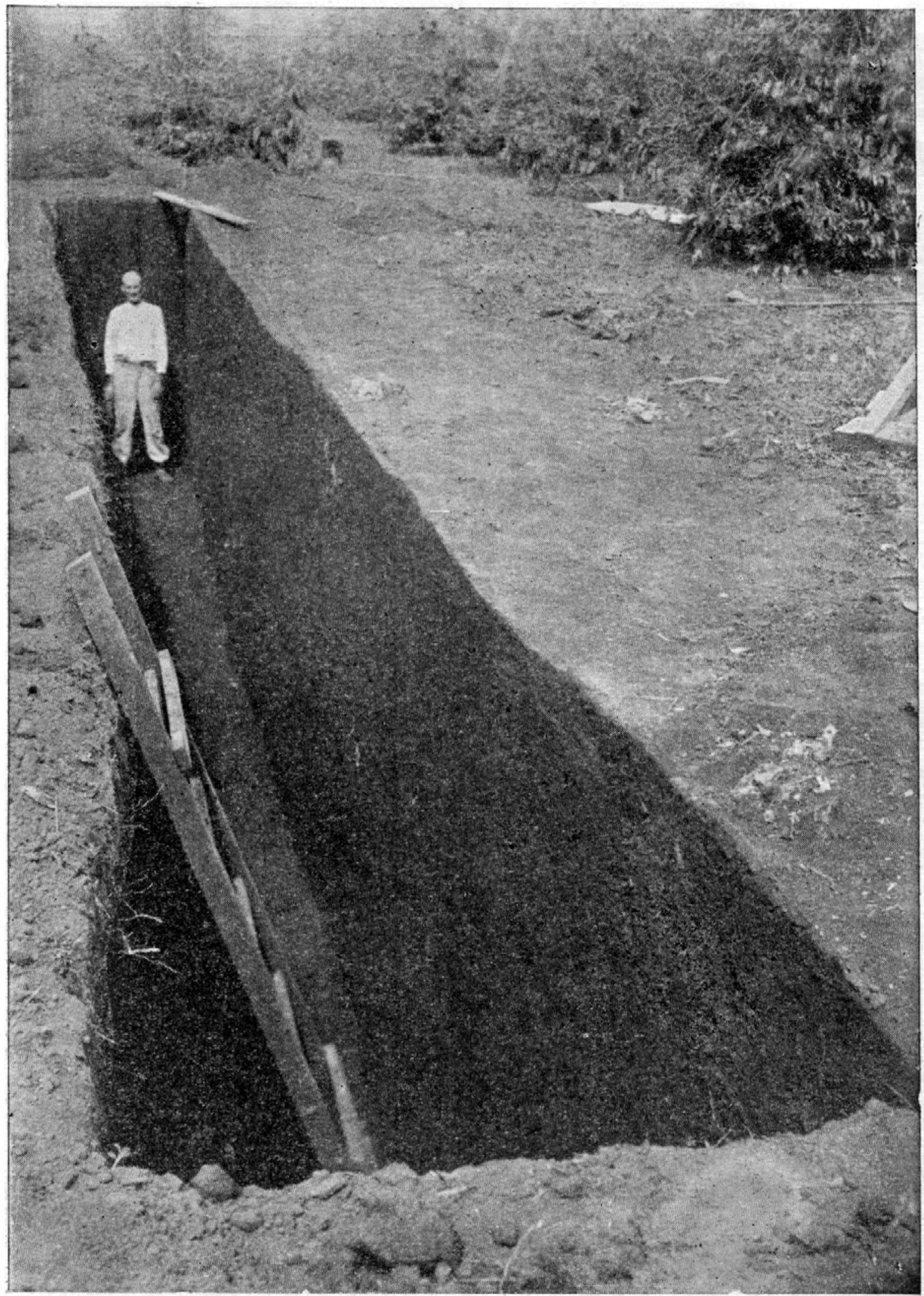

Fig. 1 -- Vilina pronta para o etudo do sistema ratirular do eafeciro. (Note-se na margem direila da mesma, vesígios dens eafeciros cortados). 


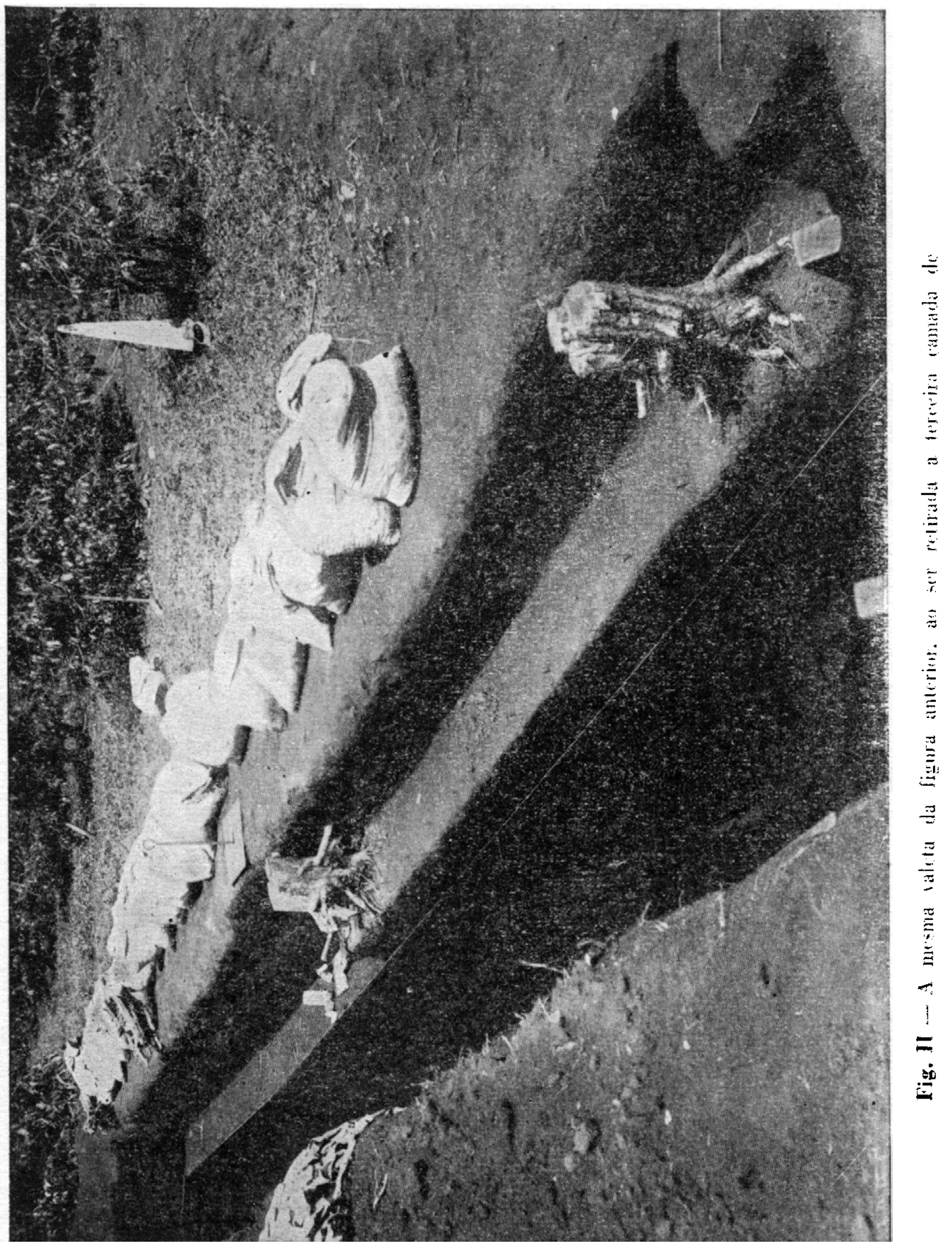




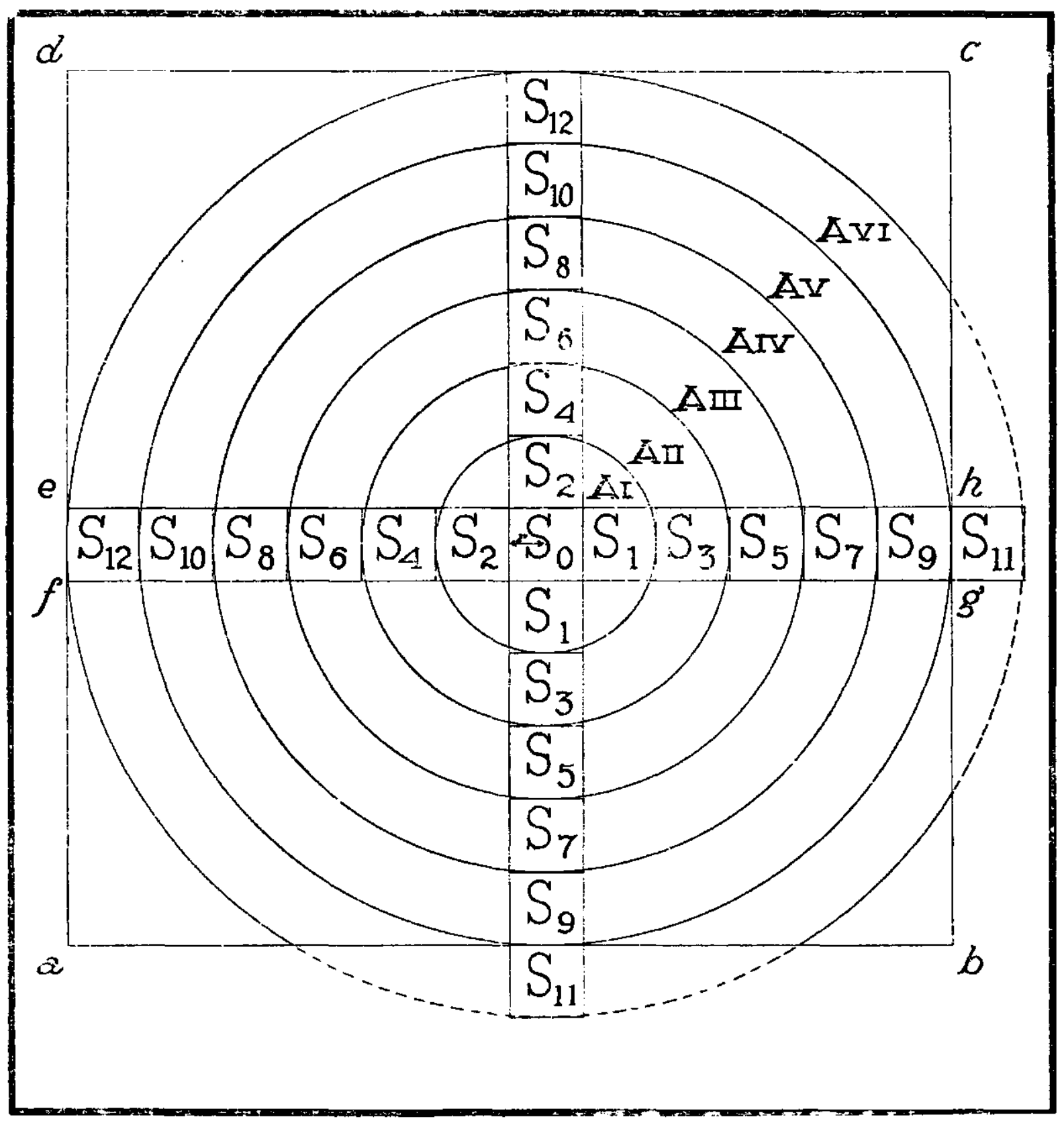

Fig. 111 


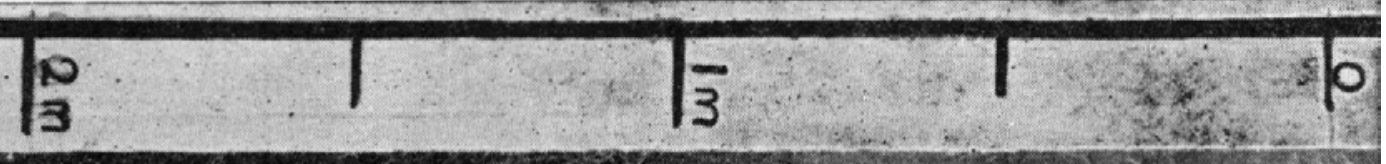

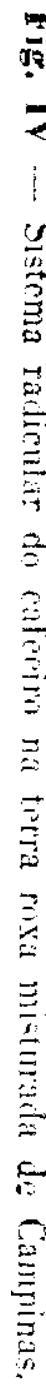

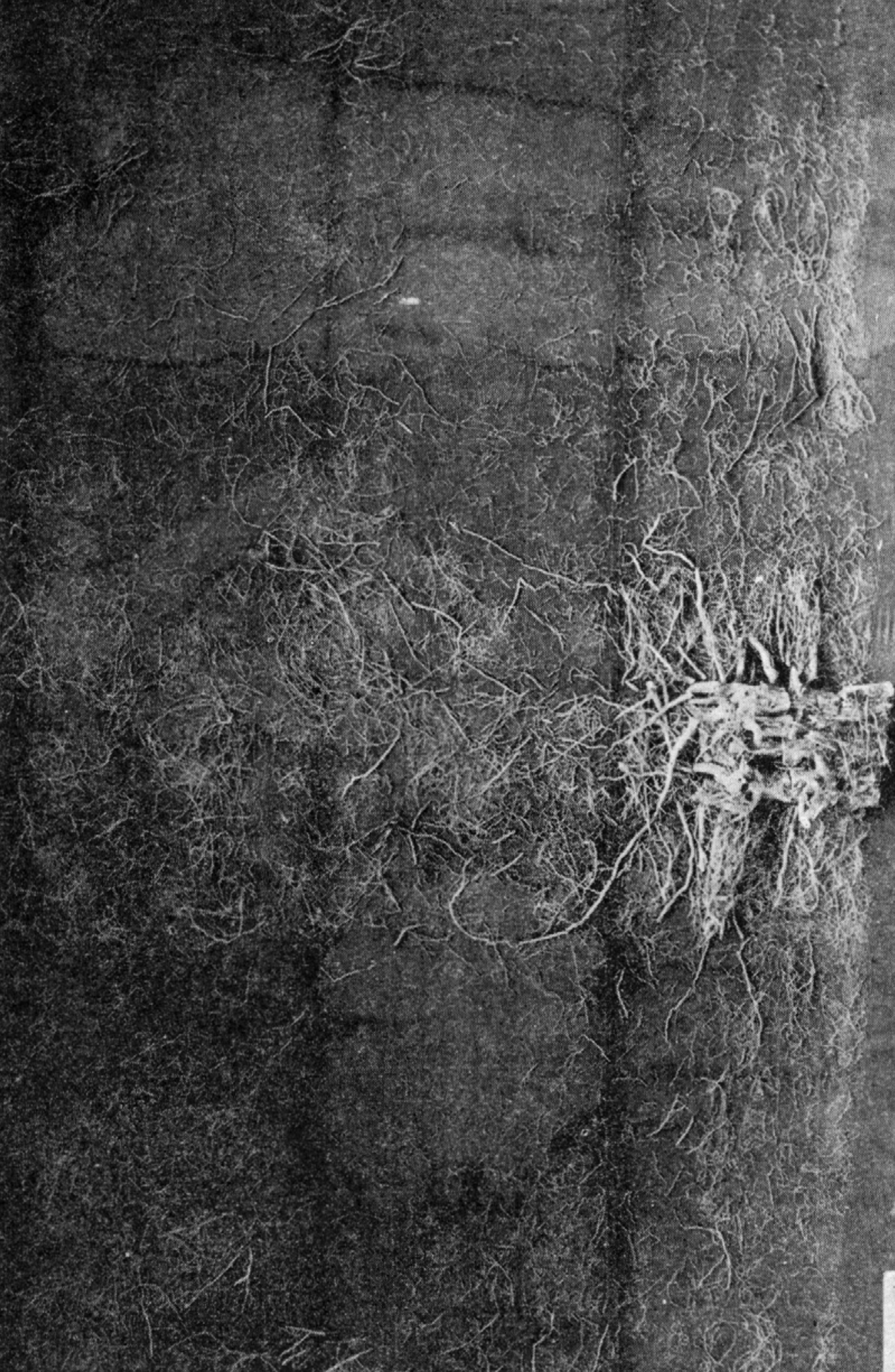




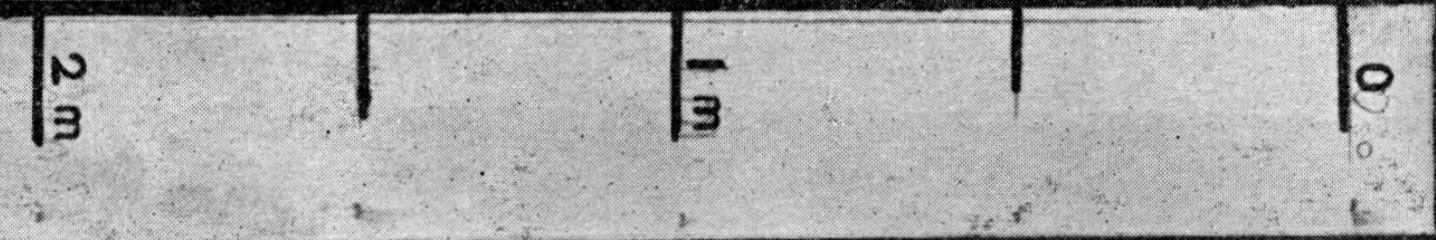

告

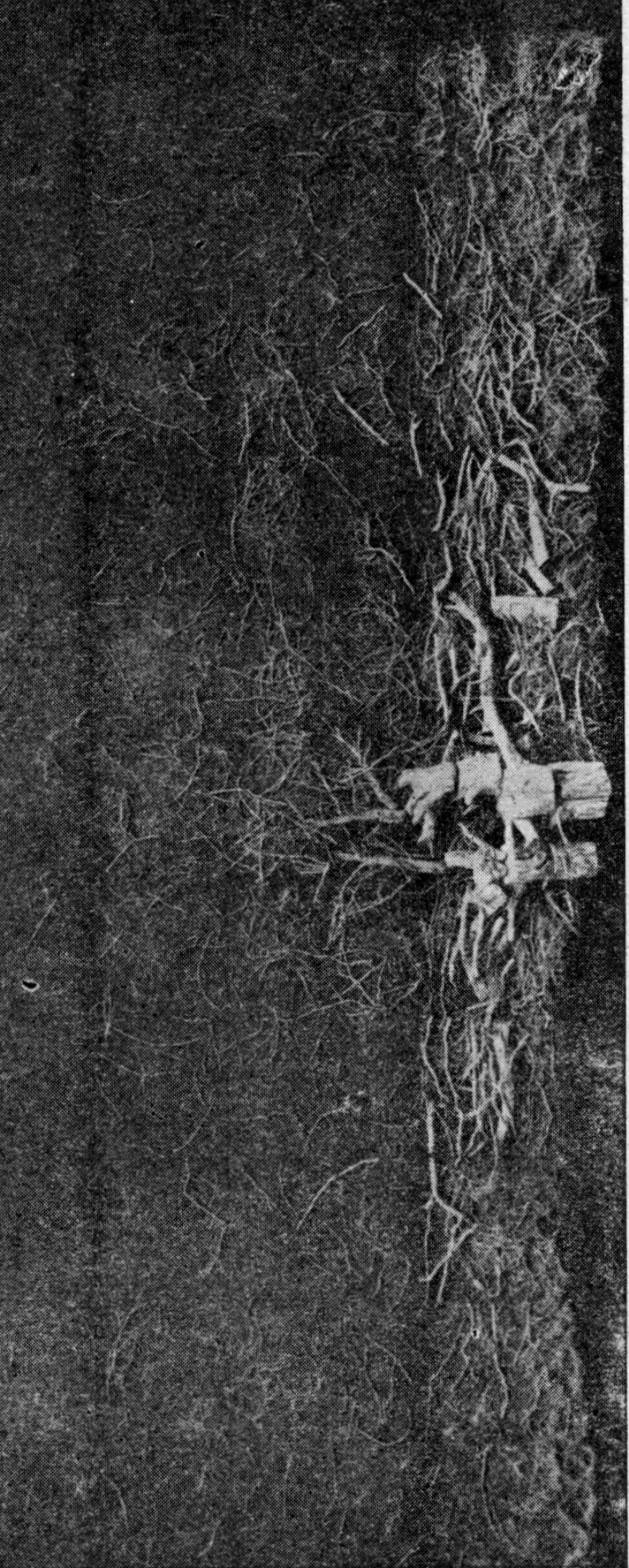




\section{$\int_{3}^{2}$}

$$
\text { - } \quad \frac{1}{3}
$$

10

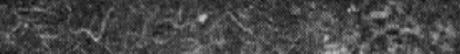

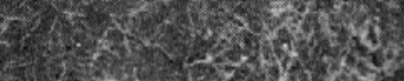
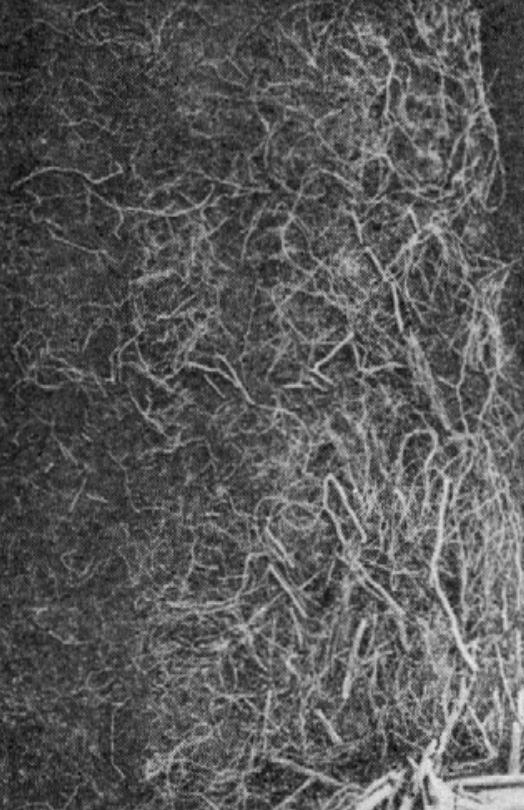


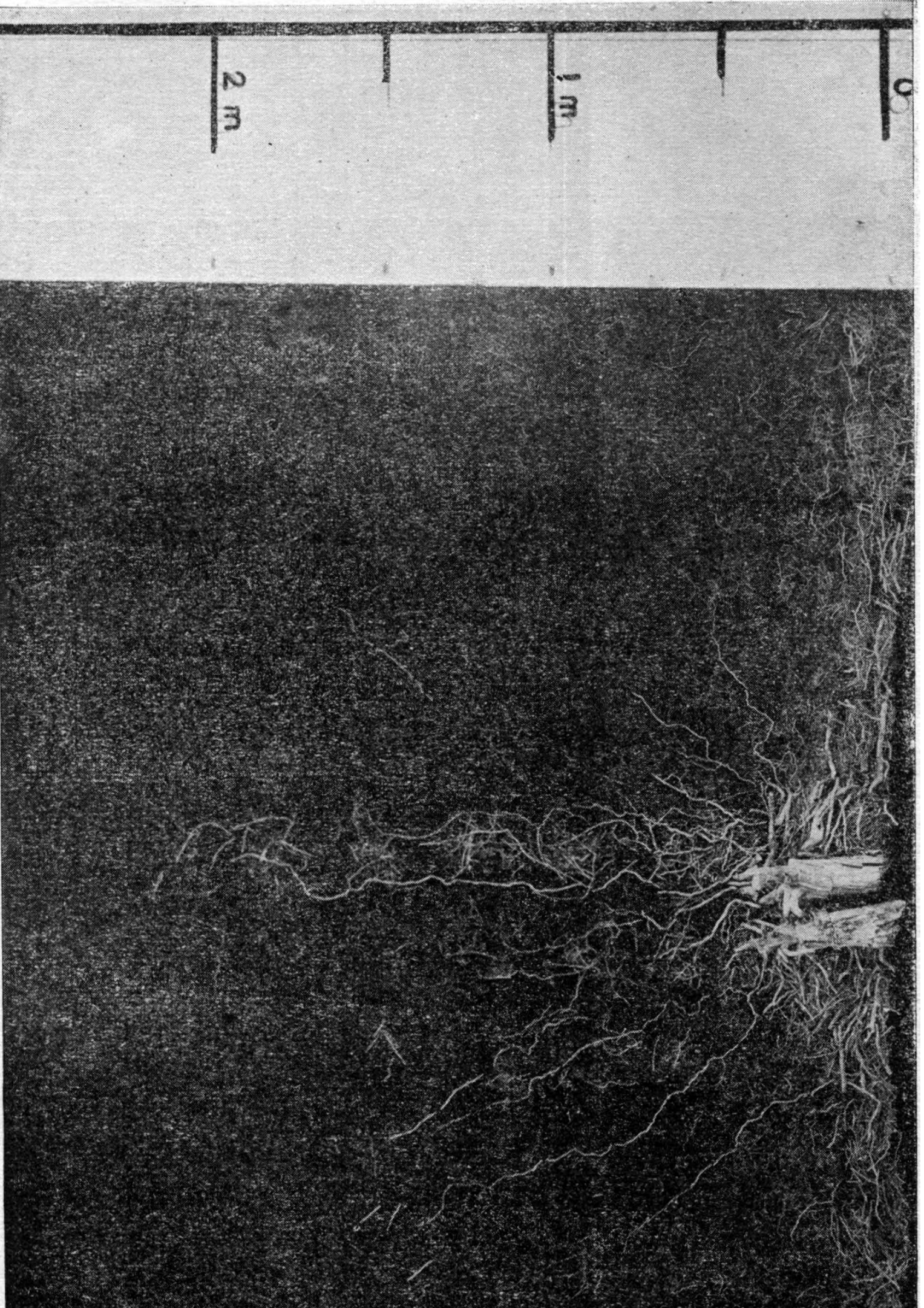




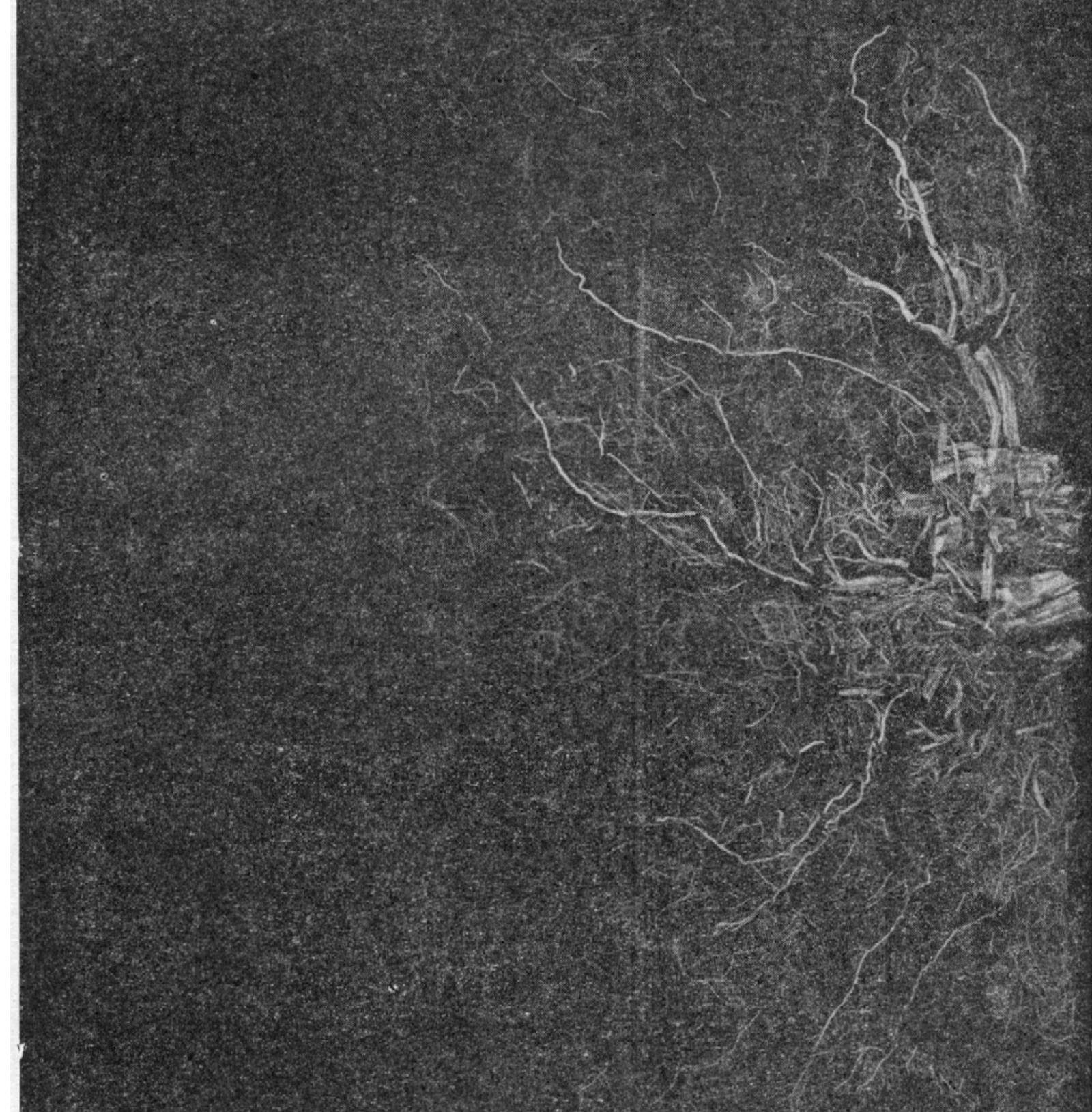

